University of Redlands

\title{
San Bernardino County Cultural Asset Mapping with VGI
}

\section{A Major Individual Project submitted in partial satisfaction of the requirements for the degree of Master of Science in Geographic Information Systems \\ by}

Fahad M. Dalbouh

Fang Ren, Ph.D.,Committee Chair

Mark Kumler, Ph.D.

December 2016 
San Bernardino County Cultural Asset Mapping with VGI

Copyright (C) 2016

by

Fahad M. Dalbouh 
The report of Fahad M. Dalbouh is approved.

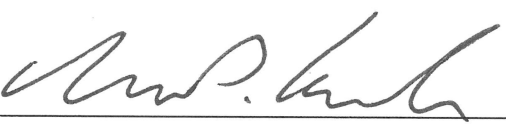

Mark Kumler, Ph.D.

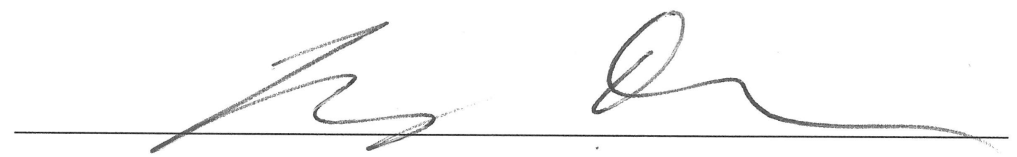

Fang Ren, Ph.D., Committee Chair

December 2016 



\section{Acknowledgements}

First and foremost, I would like to thank the almighty Allah for giving me the strength and the composure to complete this project.

I would like to directly thank my advisor, Dr. Fang Ren, for her support, advice and encouragement. I sincerely appreciate your hard-working nature and the dedication that you have always shown. It is a measure of your success and popularity amongst all the other faculty I have met. I would also thank my examiner, Dr. Mark Kumler, who had never held back his worthy consultation and guidance.

I would like to extend my thanks to the MS GIS program: from faculty, administration and staff, and to all the students who have made my stay here worth it. I say "Keep it up!" I have learned a lot, and I truly appreciate all your guidance and friendship during my time here. I would also like to express my thanks and appreciation to Stephen Klein for his cooperation, edits and guidance throughout the program. To Faisal Basudan, Omar Bugshan, Abdullah Shubayli, Abdulelah Aljudibi, and Ammar Mandourah, I was lucky and glad to have all of you in the program, you made my stay more comfortablelike I was at my home.

Additional thanks go to the members of the General Commission Survey, for offering me the scholarship to come and learn at the University of Redlands.

I would also like to seize this opportunity to extend deep regards to my project client, Mrs. Danielle Giudici, for providing me with the original concepts, the required data and for all her cooperation in completing this project.

Finally, many many thanks to my family, who have always stood by me and given their full support. I want to express deepest gratitude to my wife Sarah for her unlimited support and patience during my absence, and her bearing the responsibility of our small daughter alone. l couldn't have achieved any kind of success without their love, support and understanding.

Thank you all...

Fahad Mohammed Dalbouh, December 2016 


\section{Abstract \\ San Bernardino County Cultural Asset Map with VGI}

by

Fahad M. Dalbouh

Cultural asset mapping is an important project for the Arts Connection, a nonprofit art organization in San Bernardino County, to raise public awareness about local culture assets and enable residents to identify more cultural assets. To address their need, this project aimed to develop a new web application to replace the existing Geoform application to allow residents to visualize, query, locate, and identify cultural assets in San Bernardino County. An ArcGIS Online web map was developed with various widgets within the integrated edition of the Web AppBuilder for ArcGIS (WABA). With the new web map application, the artists, residents, and community development practitioners can reflect on what makes their communities unique and how geospatial analysis can be leveraged to achieve broader community development goals. 



\section{Table of Contents}

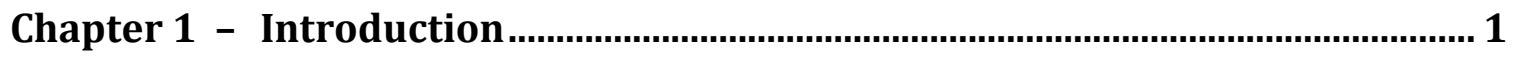

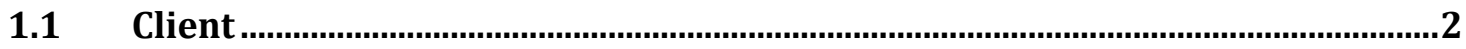

$1.2 \quad$ Problem Statement .....................................................................................

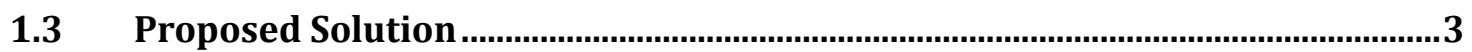

1.3.1 Goals and Objectives ...........................................................................................................

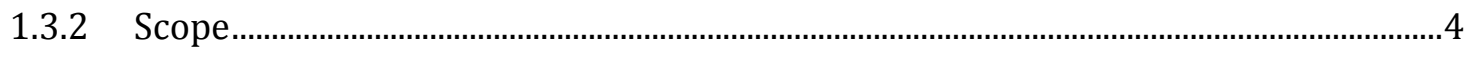

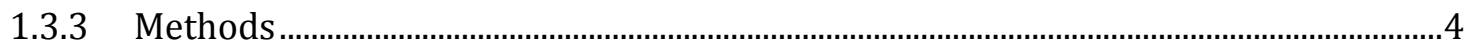

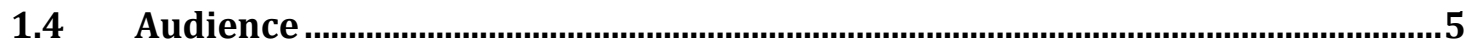

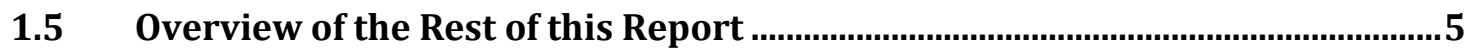

Chapter 2 - Background and Literature Review …............................................... 7

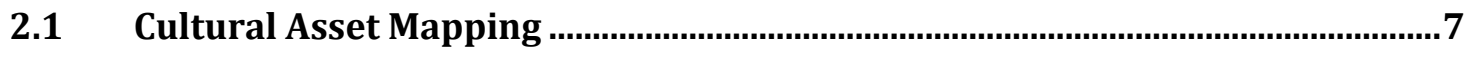

2.2 GIS and Volunteered Geographic Information................................................ 10

$2.3 \quad$ The Development of Web GIS ..................................................................... 12

$2.4 \quad$ Summary

Chapter 3 - Systems Analysis and Design ........................................................15

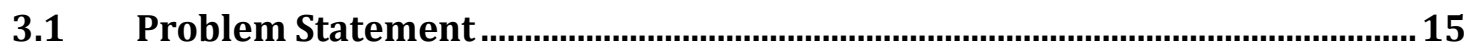

3.2 Requirements Analysis....................................................................................15

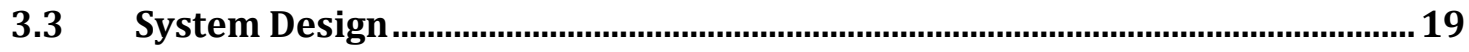

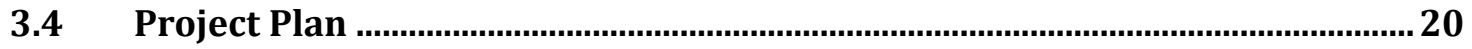

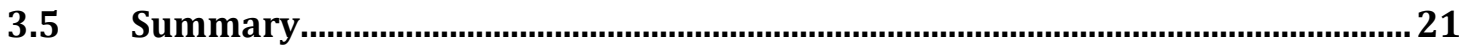

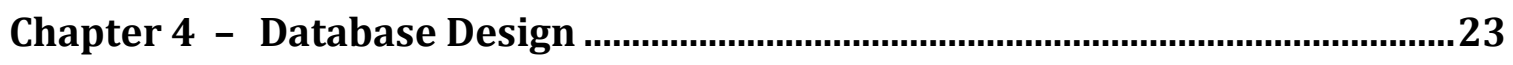

4.1 Conceptual Data Model..................................................................................23 


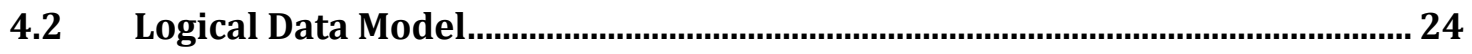

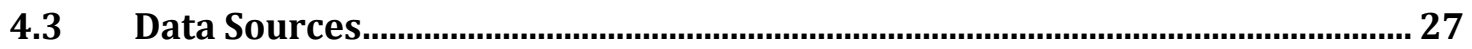

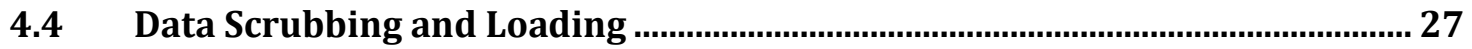

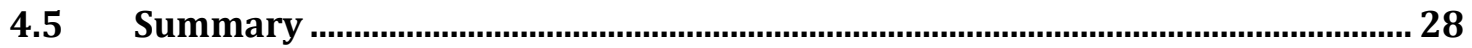

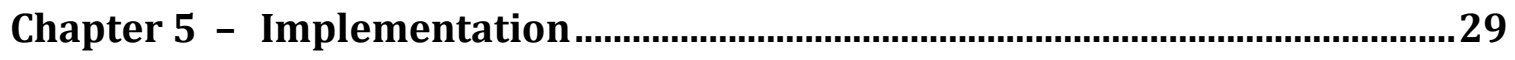

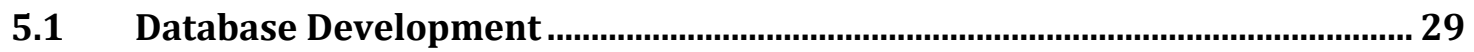

5.1.1 Creating a Cultural Asset Geodatabase ........................................................................... 30

5.1.2 Maintaining Database Integrity Using Subtypes and Domains....................................30

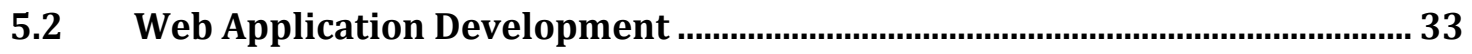

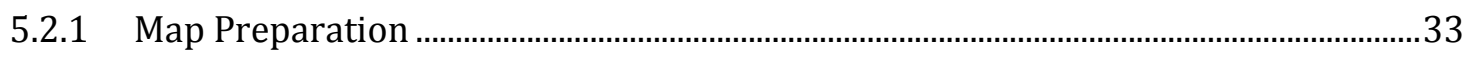

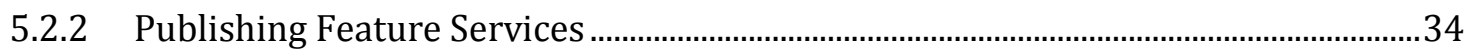

5.2.3 Creating and Configuring the Web Map ...................................................................... 37

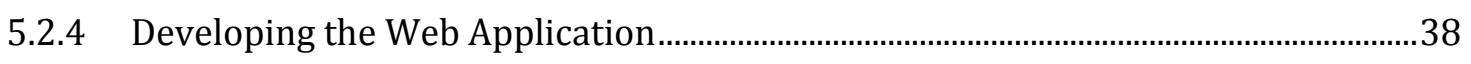

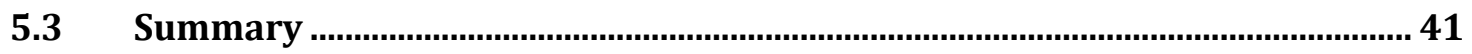

Chapter 6 - Use Cases and Results.....................................................................43

6.1 Browsing the Culture Assets in San Bernardino County ....................................43

6.2 Editing the Culture Asset Dataset....................................................................... 48

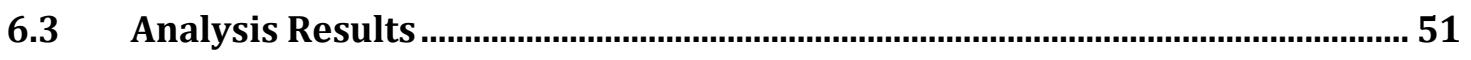

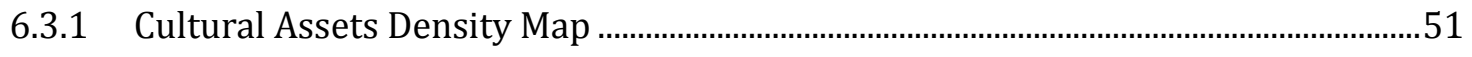

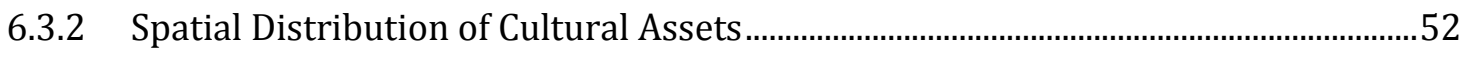

6.3.3 Spatial Proximity between Cultural Assets and Population ........................................56

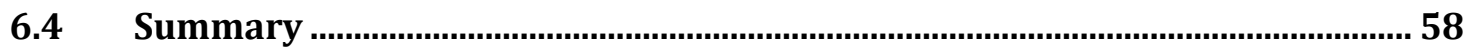

Chapter 7 - Conclusions and Future Work ….......................................................59

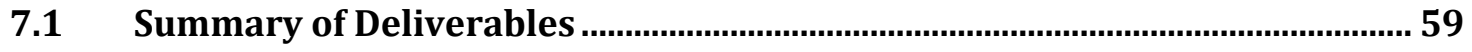




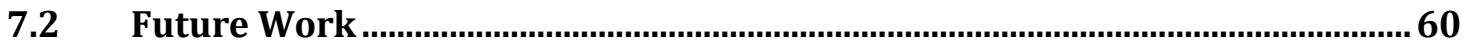

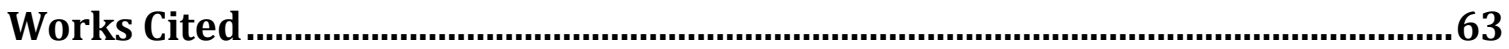




\section{Table of Figures}

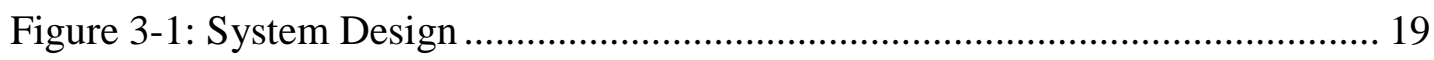

Figure 4-1: Conceptual Data Model ................................................................... 24

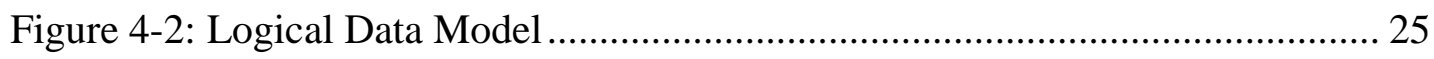

Figure 4-3: Geodatabase Representation for Cultural Asset Feature Class .............. 26

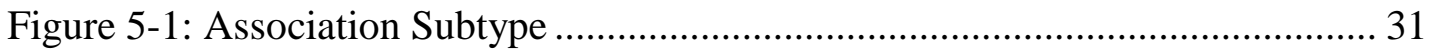

Figure 5-2: Map Document to Be Published......................................................... 34

Figure 5-3: The ArcGIS Online for Organizations Login through ArcMap .............. 35

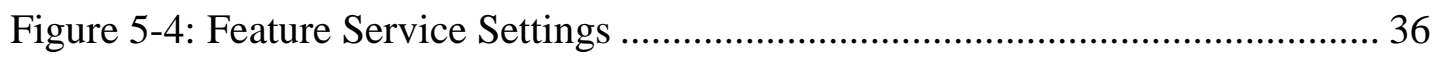

Figure 5-5: The ArcGIS REST Services Directory ………….................................... 37

Figure 5-6: The Workflow Tabs in Web AppBuilder for ArcGIS ............................ 38

Figure 5-7: Preconfigured Widgets and Themes in Web AppBuilder for ArcGIS ... 39

Figure 5-8: The Smart Editor Configuration Window …………................................. 40

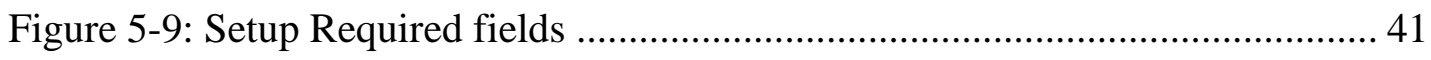

Figure 6-1: Initial Application View ................................................................... 44

Figure 6-2: Filter Widget Based on the City and Category of the Cultural Asset .... 45

Figure 6-3: A List of Cultural Assets that was Located within 5 Miles from the

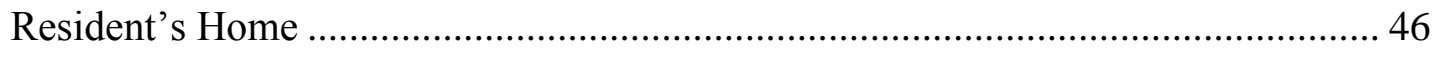

Figure 6-4: Problem of Incorrect Distance Information............................................ 47

Figure 6-5: Performing Chart Widget Capability ..................................................... 48

Figure 6-6: Editor Widget with Editing Enabled for the Cultural Asset.................... 49

Figure 6-7: Performing Attribute Editing in the Panel for the New Cultural Asset.. 50

Figure 6-8: The Final Map that Include the New Asset .......................................... 51 
Figure 6-11: Number of the Collected Cultural Assets Shown with Proportional Circles for each City in San Bernardino County ....................................................55

Figure 6-12: Comparison Spatial Distribution of People and Cultural Assets ...........57 



\section{List of Tables}

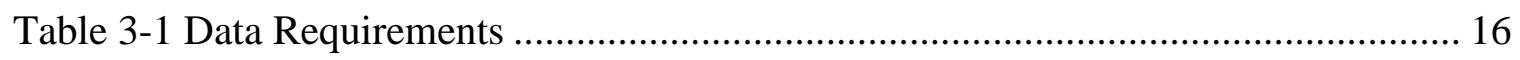

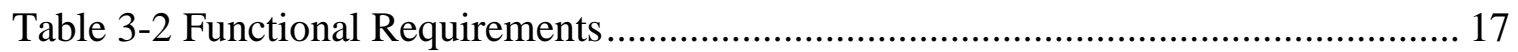

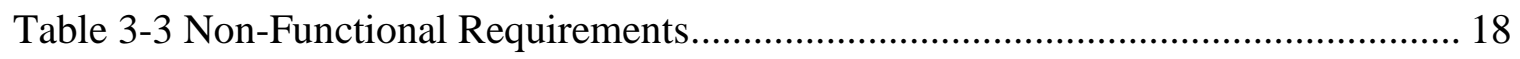

Table 5-1 Domain List for each Subtype …........................................................... 32

Table 6-1 Number of Cultural Assets by Citiy in San Bernardino County ...................... 56

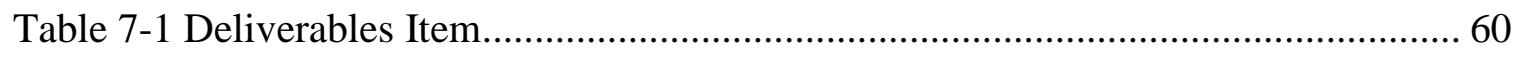





\section{List of Acronyms and Definitions}

$\begin{array}{ll}\text { AGOL } & \text { ArcGIS Online } \\ \text { ArcSDE } & \text { ArcGIS Spatial Database Engine } \\ \text { CAMP } & \text { Cultural Asset Mapping Project } \\ \text { CSV } & \text { Comma-Separated Values } \\ \text { GIS } & \text { Geographic Information System } \\ \text { GPS } & \text { Global Positioning System } \\ \text { HTTP } & \text { Hypertext Transfer Protocol } \\ \text { MXD } & \text { Map Document } \\ \text { UML } & \text { Unified Model Language } \\ \text { URL } & \text { Universal Resource Locator } \\ \text { VGI } & \text { Volunteered Geographic Information } \\ \text { WABA } & \text { Web AppBuilder for ArcGIS } \\ \text { WWW } & \text { World Wide Web }\end{array}$




\section{Chapter 1 - Introduction}

Cultural mapping has become a widely recognized tool for identifying a region's cultural assets and resources. These data are collected through a variety of methods for economic, social, and cultural development purposes. According to Stan Hagen (Creative City Network of Canada and The 2010 Legacies Now, Report, 2012), “cultural mapping is a valuable tool for identifying a community's strengths and its resources. This process can help as communities move into the planning and implementation phase by identifying early the resources, efficiencies and links between arts and cultural groups, as well as their common aspirations and values" (p.3). Many communities now start to map their cultural resources to promote a good quality of life. Arts Connection, the Arts Council of San Bernardino County, is interested in gathering local cultural asset information to enhance and develop the local communities through the Cultural Assets Mapping Project (CAMP).

There are various forms of community assets, including citizen associations (e.g. churches, recreation programs, and cultural groups) and local institutions (e.g. parks, schools, and libraries) (Kretzmann \& McKnight, 1993). Community assets can be easy to identify and map, especially when residents are involved in data collection. For example, community members can plan and conduct a cultural asset mapping event that brings together a group of residents and art organizations to identify and discuss the assets in their community. After the discussion, they can map all the cultural assets within the community and provide a way of accessing them. 
Recent technological developments, such as web GIS, have enabled new and innovative opportunities for collecting and combining data from multiple data entries. It can be used to work with community members to identify, map, plot, query, and visualize their assets with just the click of a button. Multiple users can access the same map to add points that represent assets and information about them. This project highlights the benefits that can be achieved by using GIS technology to gather cultural assets resources and engage the community with multiple points of entry for the CAMP.

\subsection{Client}

The client for this project was Arts Connection, the Arts Council of San Bernardino County. The point of contact was Danielle Giudici Wallis, the Interim Executive Director of Arts Connection. She is an artist and educator residing in Redlands, California, and an adjunct faculty member in the University of Redlands' Art Department. Wallis was interested in developing a web map application for their cultural assets, which artists can use to identify whether their current location is associated with existing cultural assets, allow residents can contribute to locate a new cultural asset, and whether there are community development officers to analyze and plan for a positive future. As such, interested users can be part of a larger group where they can develop collaborative projects that will serve their communities and provide access to the arts. The project client acted as a domain knowledge expert in the field of cultural recourses when inquires arose during development and design of the solution.

\subsection{Problem Statement}

The client, Danielle Giudici Wallis, has been working to identify cultural assets in San Bernardino County by crowdsourcing information through Geoform, an application 
developed by a volunteer at Esri, but this was not user friendly with poor functionality and clarity. This Geoform application was used to quickly collect the culture assets within the community of San Bernardino. In order to attract new interested users who can generate more data for the client, Wallis decided to replace the old web map with a new one that allows differentiating categories of assets, provides more functionality, and is more user-friendly than the previous one.

\subsection{Proposed Solution}

The proposed solution was to replace the current Geoform with a new web map application that can identify cultural assets and facilitate exchange of information between the artists, residents, and organization within the community. In order to achieve this, it was necessary to design a geodatabase to store vital cultural assets and resources. Publishing map and feature services by using the client's ArcGIS Online organizational account for the hosting and storage of data were essential elements for this solution.

\subsubsection{Goals and Objectives}

The goal of this project was to develop a solution for Art Connections to identify, collect, and visualize the cultural assets in San Bernardino County, as well to as collaborate with artists, arts organizations, art patrons, businesses, and community residents to develop projects that will serve their communities and provide better access to the arts. The objectives of this project were: to design a database to store the numerous types of the cultural assets, and to develop a web map application that allows artists, residents and those involved in community development to more easily contribute, identify, and visualize the existing cultural assets in the community. 


\subsubsection{Scope}

In order to achieve the project goal and objectives, the scope of the project had to be clearly established. The study area for this project was limited to San Bernardino County and the scope consisted of three deliverables.

The first deliverable to the client was a file geodatabase of CAMP, which contains all culture asset data of different categories in the study area and will be updated in the future by the client. The second deliverable was a web application where the public can search, query, and examine the culture assets. New data entry would be allowed through a straightforward user interface for the public and the new entry would be visible to the public once it is confirmed by the client.

\subsubsection{Methods}

The Agile development methodology was adopted in this project. One important characteristic of the agile process is it contains an iterative process that helps to complete as many development tasks as possible through increased communication. In the planning phase, the process began with a preliminary investigation of the client's needs. During this phase, the solution was defined with the client in respect to the information product that the system should provide. This involved data requirements, functional requirements and system requirements.

In the design phase, the conceptual and logical models were built based on how the client categorizes the diversity of cultural assets. Then, the physical geodatabase was created within ArcGIS Desktop 10.3 according to the client expectations.

The development phase of this project consisted of two tasks. Esri products were used since the client has been using this software for their existing web map. The first 
task in the development phase was to geocode addresses using the World Geocoding Service for address from ArcGIS Online and to migrate the existing data to the new database. The second task was to develop the web map application, which includes map document preparation, publishing feature services, and configuring the web map application using the integrated edition of Web AppBuilder for ArcGIS (WABA). Prior to the deployment of the web map application, it was tested locally to ensure that it performed all functions to meet the client's requirements. Finally, the web map application was deployed to the production environment of the client's organization.

\subsection{Audience}

The project targeted a broad audience within San Bernardino County, including the Arts Connection (the Arts Council of San Bernardino County), artists, arts organizations and administrators, art patrons, community development officers, citizen associations, local institutions, and businesses. The web map application was developed for the public with an introductory knowledge in GIS to be able to use and understand since they are the source of the information.

\subsection{Overview of the Rest of this Report}

The rest of this report consists of six chapters. Chapter Two provides background material and a literature review of previous work done in the fields of cultural asset mapping and web technology. Chapter Three describes the systems analysis and design of the project. Chapter Four illustrates the appropriate design model that met the client's needs. Chapter Five focuses on the implementation of the database and the web map application. Chapter Six offers two use cases for the developed application: browsing and 
editing the data. Chapter Seven includes a conclusion and highlights potential future work. 


\section{Chapter 2 - Background and Literature Review}

This chapter provides an overview of three main aspects that are relevant to this project.

Section 2.1 discusses the concept and importance of cultural asset mapping. The power of geographic information system (GIS) and volunteered geographic information (VGI) are covered in Section 2.2. Section 2.3 introduces the basic concepts and benefits of web GIS applications, and it highlights some previous works.

\subsection{Cultural Asset Mapping}

Cultural asset mapping is the process of gathering, recording, scrutinizing and categorizing information to define the cultural resources, networks and practice of arts within a given community (Voigt, 2011). It is an efficient way for identifying the resources that every community has. It also engages local creative groups in the development of a project and to recommend strategies that leverage cultural assets. Each cultural asset mapping project has its description of cultural assets depending on the purpose of development. According to the Willowbrook project report, cultural assets include people, places, and organizations that support the contribution of community members in matters to do with arts, culture and creativity (Los Angeles County Arts Commission, 2013).

Cultural asset mapping is important in many ways (Blais, 2014). Cultural asset mapping plays a valuable role in the planning phase, as it allows government officials to quickly identify and collect resources earlier and create links between the arts and cultural groups by engaging the community residents in the planning process through a community survey or an interactive mapping exercise. The community residents then are able to help identify cultural assets within their community. The process thus helps to 
reduce time and cost. For example, Hennepin Theater Trust in Minneapolis was supported to develop cultural mapping exercise that connected arts organizations, local communities, and institutions to improve and revitalize the Hennepin Avenue as a cultural corridor (Blais, 2012). It also helps to connect developers and investors with potential decision-makers such as leaders, organizations, and members of the public. Developers and investors can engage stakeholders to gather and share cultural asset information through partnerships and organization links. By identifying cultural assets and the challenges that the community faces concerning cultural diversity, they can tailor their enterprise to the society that it is intended to serve.

Cultural asset mapping plays a major role in economic development. It supports in identifying cultural assets used in creating information about community cultural development agendas. Various agencies can rely on cultural asset mapping as a tool for evaluating their resources and distributing them equally. It can also be used to find gaps in current policies or integrated with other variable factors to analyze the effect of these factors. For instance, mapping cultural assets along with demographic variations, such as income levels and ethnic diversity, can be analyzed to determine whether they had an impact on the presence of cultural assets and (or) improvement; it could be also implemented within other cities to establish a culturally sustainable community. For example, while trying to evaluate the correlation between ethnic diversity and income levels, the City of Portland, Oregon, developed a GIS application to map cultural contributions and arts education programs in the city's neighborhoods (Portland State University, 2010). This application allows city staff to identify areas where cultural assets are concentrated, lacking, or distributed unevenly. 
Cultural asset mapping is a valuable tool in the promotion and protection of culture. Through cultural asset plans, societies can safeguard their arts and cultural assets. As previously stated, cultural assets acquire different meaning depending on the purpose of the cultural asset mapping. There is often a lack of awareness of the breadth of cultural resources and activities readily available. Cultural asset plans are not only relevant to the residents; they also encourage tourism. By consolidating information on cultural assets, they become accessible — hence available to tourists and community members (Blais, 2014).

Last, cultural asset mapping protects culture properties of a community and educates its residents to safeguard them. By mapping cultural resources, organizations and groups that promote culture can interact and embark on building a sustainable cultural community. An excellent example is the Cultural Asset Mapping Project, developed in Austin, Texas. It connects heritage, art, cultural assets and other creative resources that are important and valuable to residents through an interactive mapping exercise, community meeting, and an online survey (City of Austin, 2016). The project aims to collaborate with the community residents in identifying these assets from their perspective to protect them and make individuals feel encouraged and motivated. Therefore, their interests towards the project will grow stronger. A similar project was also observed in the Town of Newmarket, Ontario, Canada, where they developed a web map application for collecting suggestions about community stories and additional resources (Blais, 2012). 


\subsection{GIS and Volunteered Geographic Information}

GIS technology allows users to digitally capture, analyze, store, and display information that is referenced to its spatial location. This technology has developed so rapidly, especially over the past two decades, that it is now accepted as an essential tool for mapping geographic phenomena. The power of this system becomes very evident when dealing with the diversity of cultural assets. For example, GIS has been applied to develop assessment maps that showed archeological sites (Wilson, 2004). The indigenous assets were identified, and the data were translated into formats that are compatible with the GIS for further analysis. Various states have applied this system to the process of mapping cultural resources and creating plans as well. For example, to understand the key networks that form the neighborhood and the possible gaps, Chicago and Toronto applied GIS in planning cultural organizations and companies in the communities (Baeker, Bulick \& Stasiuk, 2005). In Ontario, the system was used to map existing community plans onto areas while making connections between them and cultural opportunities.

Volunteered Geographic Information (VGI) is the collection of geographic information that is sourced from the public. VGI is a special case of the community based data collection model in which the information content is created by end users (Agrios \& Mann, 2010). VGI along with GPS-enabled smart phones can allow various organizations to collect real time information to their application and database, speeding up the display, analysis and decision making by using up to date information. For example, the cities of Los Angeles and Pasadena have used the VGI approach when developing mobile applications. This application enables the community residents to track and report graffiti 
removal, property violations, street sweeping and so on (Fu, 2015). In addition, many websites such as SeeClickFix and WikiMapia used VGI along with web based technologies to collect data, identify problems, and provide solutions to the problems as well (Fu \& Sun, 2011).

While the power of VGI in data collection has been recognized, the data quality issue with VGI has also been discussed. With the outburst of social media, one cannot ascertain the originality of the information rendered or the degree of the voluntary aspect ascribe to the contributors of geographical material (Sui, Elwood, and Goodchild, 2012). VGI lacks standardization as the source of data is from different varying sources. This lack of conventional way of analyzing the VGI data compromises its quality and few people are able to trust the information provided in the VGI databases. The other issue with VGI is the aspect of various points of interest that are uploaded into the VGI pool database. For example, different users may upload the same landmark but indicate different names and locations. This problem affects specific individuals who want to locate a specific place (Senaratne, Mobasheri, Ali, Capineri, \& Hacklay, 2016). Another concern is how vaguely human beings are able to conceptualize locations, as the geographical features keep on changing, and this limits the understanding of many people and hence compromises the quality of VGI. Also, if a mistake is made by the sender, there is no mode of correcting it hence there may be incidences of erroneous data posted hence compromising the quality of VGI (Senaratne et al., 2016). 


\subsection{The Development of Web GIS}

Web GIS is any form of GIS that uses web technology to communicate between a server and a client. It is limited to using the World Wide Web and the HTTP to influence spatial data. This role minimizes the constraints, such as the time and location of distributing and processing spatial data. Favretto (2010) describes a web GIS as being a map server that is given the responsibility of depicting maps that are explored by the web browser clients, on the basis of the spatial evaluation performed by the GIS. Web GIS is clearly different from VGI but they both play a role in the production and transfer of geographical information to users and customers.

There are numerous advantages associated with the use of web GIS (Fu, 2015). First and foremost, it allows usage by a large number of consumers simultaneously. As a result, the web GIS offers greater performance and scalability compared to the traditional desktop GIS. Second, it offers better cross-platform capability for its users by supporting different operating systems such as Microsoft Windows and the Apple Macintosh operating system. Third, it is cost-efficient to manage, as one is able to set up one web GIS for use and access across the board to numerous users. For instance, a collaborative web application enabled researchers to visualize the migration patterns of the Lebu people from their original villages to the Cap-Vert peninsula in Senegal, West Africa. The web application also improved the database by allowing researchers to contribute their insight on the Lebu migration (Guidry, 2011). Fourth, web GIS provides unified updates - since an update is only done on the application server, it also applies to all clients, which, in turn, saves time. Last but not least, web GIS is easy to use and very accessible through HTTP due to its broad spectrum. An example of this can be found in 
Hutsel (2012), where the author built a web GIS application so that the Economic Department of the City of Highland, California, and other government departments could have easy access to the spatial data and view it from diverse sources. The decisionmaking process improved at the same time, files are effortlessly traced, and users are able to simply view, add, and receive clarifications concerning any query about the records.

\subsection{Summary}

The main goal of this project was to develop a web map application that collects information to help the Arts Connection better understand local arts-where cultural events are being held, who is making art, which organizations are participating in or benefitting from art and how community development can be supported. The combination of GIS, VGI, and web technologies were determined to be the solution to collect, store, visualize, identify, query and access geospatial data via the Internet. This is because they can offer a cost-effective way to collect data by involving the community in the process of data collection. They can also be used to map the supply and demand for cultural activities, thus enabling planning issues to be visual and meaningful. 



\section{Chapter 3 - Systems Analysis and Design}

Systems are created in order to solve customers' problem. The development of the system consists of two major components: requirements analysis and design. The process goes from the blueprint to the actual products. This chapter elaborates the requirements of the system, the major components of the system, and the project plan. Section 3.1 outlines the client's problem. The requirements analysis of the project is discussed in Section 3.2. This involved gathering the required specifications of the data, and the functional and non-functional aspects of the system. Section 3.3 describes the system interface with identifying the high-level components of the system and how they communicate with each other. The project plan that was used to develop and implement the proposed solution is described in Section 3.4. The chapter ends with a summary in Section 3.5.

\subsection{Problem Statement}

The client wanted to replace their existing Geoform web map with a new one. The old version does not allow differentiation of assets categories and lacks of functionalities that the client desires. The client wanted to extend the categories of the cultural assets and provide a quick and simple way for users to search for cultural assets and share the information with others. With the new version of the web application, the client would be able to link more people who have the same interests for developing collaborative projects that will serve their communities.

\subsection{Requirements Analysis}

After several meetings with the client, the next step was to refine the initial requirements of the proposal system. It is important to understand and clearly define the requirements 
in order to satisfy the client's needs. This section demonstrates the results of the analysis undertaken to meet these requirements and is placed into one of the following categories: data requirements, functional requirements, and non-functional requirements.

\subsubsection{Data Requirements}

The client provided all the data required in Excel spreadsheets with addresses for the main points of interest (POIs) of cultural assets in San Bernardino County. These data were taken from the previous Geoform application along with extra data from the client. The extent of this project was limited to San Bernardino County.

Table 3-1 shows the two entities or features that were required for this project that included cultural assets in the form of point features, and the San Bernardino County boundary a as a polygon feature.

Table 3-1 Data Requirements

\begin{tabular}{|l|l|l|l|}
\hline \multicolumn{1}{|c|}{ Feature } & \multicolumn{1}{|c|}{ Data Structure } & \multicolumn{1}{c|}{ Source } & \multicolumn{1}{c|}{ Current formats } \\
\hline Cultural Asset & Vector (point features) & Client & $\begin{array}{l}\text { Excel spreadsheet } \\
\text {.xlsx }\end{array}$ \\
\hline $\begin{array}{l}\text { San Bernardino } \\
\text { County Boundary }\end{array}$ & $\begin{array}{l}\text { Vector (polygon } \\
\text { features) }\end{array}$ & Client & Feature service \\
\hline
\end{tabular}

The Cultural Asset feature contains all the information pertaining to an asset within San Bernardino County such as name of the organization, the address, the category this asset belongs to, and the sub-category associated with it. The San Bernardino County Boundary feature outlines the boundary of the county and helps map users focus on that area of the map. 


\subsubsection{Functional Requirements}

The functional requirements describe and determine the capabilities that the system should perform on the application while visitors navigate through the website. Generally, functional requirements are precise statements that represent specific actions the system must accomplish, when the user initiates an activity. For example, when the user clicks on a button labeled <home>, the system orients the map to the starting location. Table 3-2 illustrates the functional requirements for this project, clearly defining the functions to be provided by the proposed solution.

Table 3-2 Functional Requirements

\begin{tabular}{|l|l|}
\hline \multicolumn{1}{|c|}{ Requirement } & \multicolumn{1}{c|}{ Description } \\
\hline Explore Data & $\begin{array}{l}\text { This allows the user to view the distribution of the cultural assets } \\
\text { within San Bernardino County via a web map application. }\end{array}$ \\
\hline Home Button & This allows the user to zoom the map to the initial map extent. \\
\hline My Location & $\begin{array}{l}\text { This allows the user to detect the user's location and zoom the } \\
\text { map to it. }\end{array}$ \\
\hline Zoom Slider & This allows the user to zoom in and out on the web map. \\
\hline Search Bar & This allows the user to find locations on the map. \\
\hline Popup Display & $\begin{array}{l}\text { This allows the user to click on any feature to open the pop-up } \\
\text { window and view related attribute information including } \\
\text { photographs or attachments. }\end{array}$ \\
\hline User Editable & $\begin{array}{l}\text { This allows anybody in the community to edit a point's } \\
\text { geometry and attributes according to predefined categories of } \\
\text { cultural assets. }\end{array}$ \\
\hline Photo Attachment & $\begin{array}{l}\text { This allows the user to upload a photo attachment as part of the } \\
\text { editing features to enrich the feature. }\end{array}$ \\
\hline Share map & $\begin{array}{l}\text { This allows the user to share the web map via e-mail and social } \\
\text { media. }\end{array}$ \\
\hline Near Me & $\begin{array}{l}\text { This allows the user to look up what cultural assets are within a } \\
\text { buffer of a specified address or location, view more detailed } \\
\text { information and get directions to the selected feature. }\end{array}$ \\
\hline Basemap Control & $\begin{array}{l}\text { This allows the user to toggle between two different basemaps } \\
\text { using the Basemap Gallery widget. }\end{array}$ \\
\hline Map Legend & This allows the user to understand what each icon represents. \\
\hline
\end{tabular}




\begin{tabular}{|l|l|}
\hline Print Services & $\begin{array}{l}\text { This allows the user to print the current map extent from the } \\
\text { application and export it in different formats (e.g., PDF and } \\
\text { JPG) and layout. }\end{array}$ \\
\hline Filter & $\begin{array}{l}\text { This allows the user to filter a specific city and category of the } \\
\text { cultural assets to display only relevant content. }\end{array}$ \\
\hline Chart & $\begin{array}{l}\text { This allows the user to display data as a graphical representation } \\
\text { based on the total feature counts for each category of cultural } \\
\text { asset. This can be done in the current map extent or drawing a } \\
\text { graphic on the map. }\end{array}$ \\
\hline
\end{tabular}

\subsubsection{Non-Functional Requirements}

The non-functional requirements are quality attributes for that system or application (i.e., performance, security, usability and reliability) that are measurable. These requirements focus on the technologies necessary to build the system according to its specifications. Based on the existing technology and the requirements of this project, it was found that Esri software is compatible for both of them in developing the system. ArcGIS 10.3 for Desktop was used to create and maintain the database and to publish editable feature services. Access to an ArcGIS Online organizational account with privileges was provided by the client to create the map and host the feature services. The web application was developed using Web AppBuilder for ArcGIS. Table 3-3 lists the nonfunctional requirements for the project.

Table 3-3 Non-Functional Requirements

\begin{tabular}{|l|l|}
\hline \multicolumn{1}{|c|}{ Requirement } & \multicolumn{1}{c|}{ Description } \\
\hline $\begin{array}{l}\text { ArcGIS 10.3 for } \\
\text { Desktop }\end{array}$ & $\begin{array}{l}\text { The ArcGIS for Desktop platform was used for creating and } \\
\text { managing the database and publishing feature services. }\end{array}$ \\
\hline $\begin{array}{l}\text { ArcGIS Online } \\
\text { organizational } \\
\text { subscription }\end{array}$ & $\begin{array}{l}\text { An organizational subscription was required to host } \\
\text { editable feature services and create the map. }\end{array}$ \\
\hline $\begin{array}{l}\text { Web AppBuilder } \\
\text { for ArcGIS }\end{array}$ & $\begin{array}{l}\text { Web AppBuilder for ArcGIS was used to design the user } \\
\text { interface and build the web map application. }\end{array}$ \\
\hline
\end{tabular}




\begin{tabular}{|l|l|}
\hline Browser Support & $\begin{array}{l}\text { The web application can run in any of the following web } \\
\text { browsers: Chrome, Firefox, Safari } 3 \text { and later, and Internet } \\
\text { Explorer 9 and later. }\end{array}$ \\
\hline User Manual & $\begin{array}{l}\text { The manual provides simple step-by-step guidance on how to } \\
\text { perform an edit task. }\end{array}$ \\
\hline
\end{tabular}

\subsection{System Design}

After analyzing the client's requirements for the proposed solution, the next step was to outline the system design. By doing this, several technologies were chosen based on their reliability and the demand for system functions in creating the client's information product as needed. Also, understanding the relationship between the basic components of the technology system was helpful to determine the configuration of the system interface and network communication. To meet the client's requirements, it was determined that a system based on the ArcGIS environment was needed. The system consisted of four major components: geodatabase, ArcGIS Online, web application, and the client (desktop or web browser). Figure 3-1 shows an overview of the system interface, the related major components and how they interact and communicate with each other.

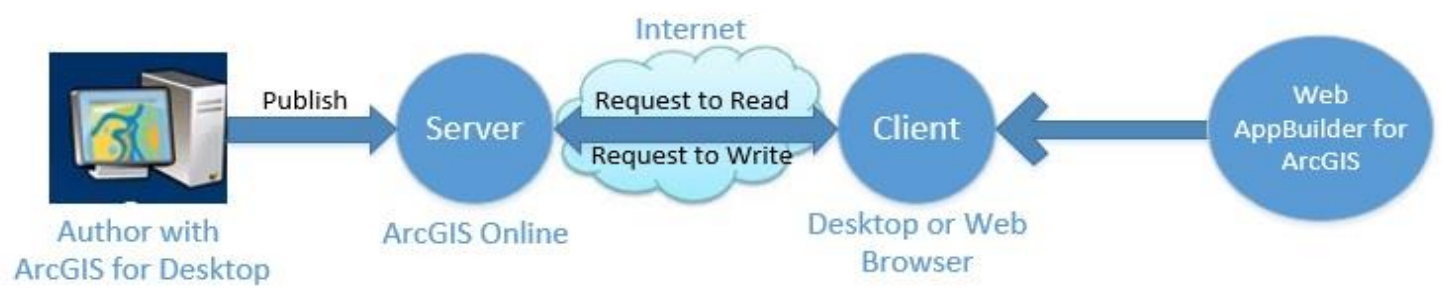

Figure 3-1: System Design 
The geodatabase component was designed to include data that will most benefit the client's organization and identify what data can and will be stored. This component involved creating, cleaning, and managing the data inside the file geodatabase within the ArcGIS 10.3 for desktop environment. Also, the ArcGIS for Desktop platform was used for publishing feature services. The ArcGIS Online platform was used to host all the feature services of the project. The map itself was authorized and published using ArcGIS Online, and it runs on a cloud-based mapping platform. The web map application was built for the San Bernardino community to enable people to view, locate, and contribute to the data collection of cultural assets. Web AppBuilder for ArcGIS (WABA) was used to develop the web application. The community can access the web application using a browser-based application on a desktop, smartphone or tablet. All of these components were assembled to deliver the desired Cultural Assets Mapping Project (CAMP) to the audience on a web browser.

\subsection{Project Plan}

The first part of the project plan was to complete the planning phase for project requirements. This phase focused principally on reviewing and analyzing the client's requirements. The second phase, design, was to be completed in mid-July 2016. This phase included the process of creating the conceptual and logical data model based on discussion with the client in the previous phase, and looking at the data source made available by the client to see what data were missing or unnecessary. The third phase of this project consisted of two tasks, and completion was expected to be in late September 2016. The first task in the development phase was to build the physical database and to migrate the existing data to the new database. The second task was to develop the web 
map application, which included map document preparation, publishing feature services, user interface design, and configuration of the web map application using the WABA (integrated edition). In the final phase, the data and the web map application were deployed to the ArcGIS Online organizational account for storage and hosting. Each Phase of the project plans included milestones accepted by the client.

\subsection{Summary}

This chapter discussed the client's requirements, the system design, and the project plan. Based on the proposed solution and the system design previously discussed in this report and the availability of existing software, it was found that both models are suitable for ArcGIS Online, giving the organization a choice that would not double its maintenance costs and would be far more valuable to them in the future as well as for now. This is because ArcGIS Online and Web AppBuilder for ArcGIS are commercial off the shelf (COTS) products and nothing is custom developed. The project plan was set up according to the number of tasks that are required for the implementation phase of this project. 



\section{Chapter 4 - Database Design}

Database design is crucial to a reliable and efficient information system. The design of a database has to do with the way data is stored and how the data is organized. Therefore, the first step in designing a GIS database for any system is to analyze the data requirements by determining the purpose of the database and how it is to be used. This chapter describes and outlines the steps in the geodatabase development process. Section 4.1 discusses the conceptual database model, which follows findings of requirements analysis, and results in a high-level definition of the information contents of the future database. Section 4.2 represents the logical data model which is derived from the conceptual data model. Data sources will be discussed in Section 4.3. Resolution of major data quality problems will be described in Section 4.4. A summary of this chapter will be found in Section 4.5 .

\subsection{Conceptual Data Model}

In order to meet the requirements given by the client, the high-level entities or classes and their relationship within the future database needed to be identified. Figure 4-1 shows the conceptual data model, which captures the overall structure of the database in this project. It is not expected to be a physical representation of the database; it is only a broad overview of the major components of the client's problem. 


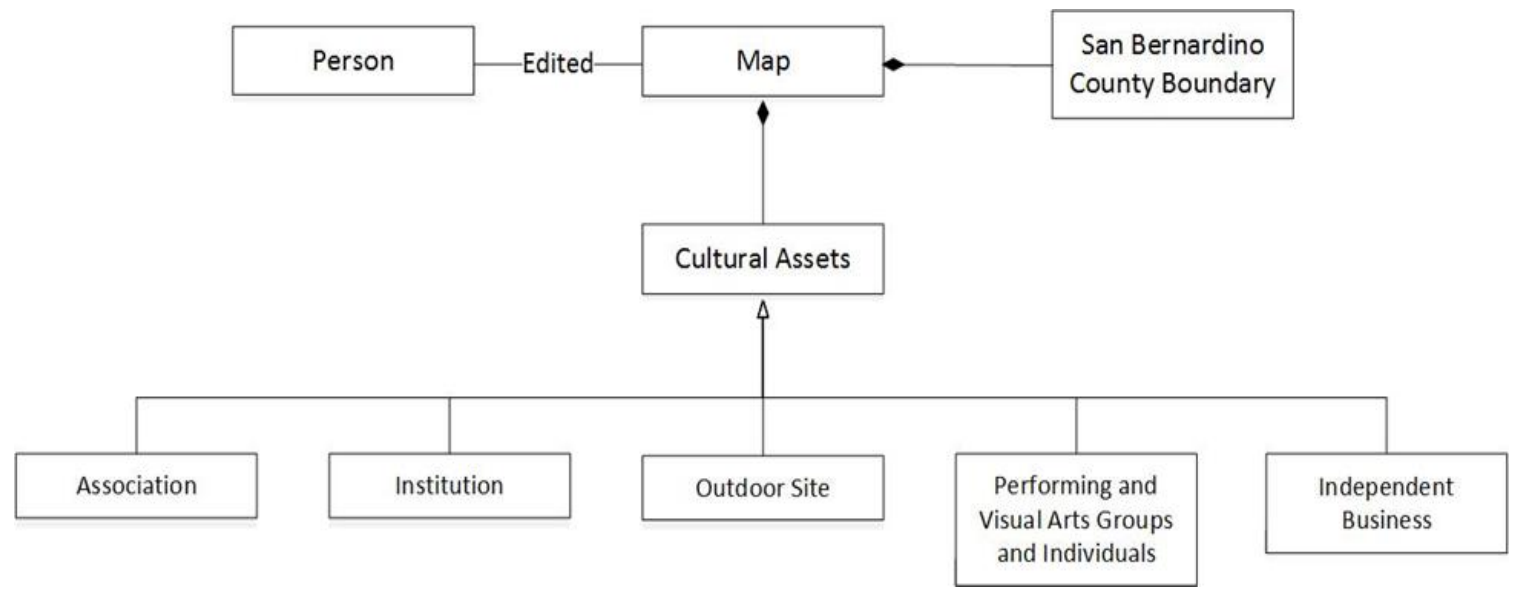

Figure 4-1: Conceptual Data Model

In the data provided by the client, three main entities were determined for this project: Cultural Assets, San Bernardino County Boundary, and Person. The Cultural Assets provide an inventory of key cultural resources that can provide access to the arts. This entity has five categories or subtypes, which will be discussed later in this chapter. These five categories were identified by the client, who is an expert in the field of cultural resources. San Bernardino County Boundary was used to show the limit or border of San Bernardino County. The Person is the source of the data, and this can be anyone in the community. It was used to describe public engagement by providing basic editing capabilities for any of these categories in a web map.

\subsection{Logical Data Model}

The logical data model illustrates and organizes the structure of the information content, in the form of tables and Unified Modeling Language (UML) diagrams that define the entities and their geographic representation. The logical model derived from the conceptual data model defines in detail the data types, attributes (type and size), relationships and rules that are required by the database (Figure 4-2). 


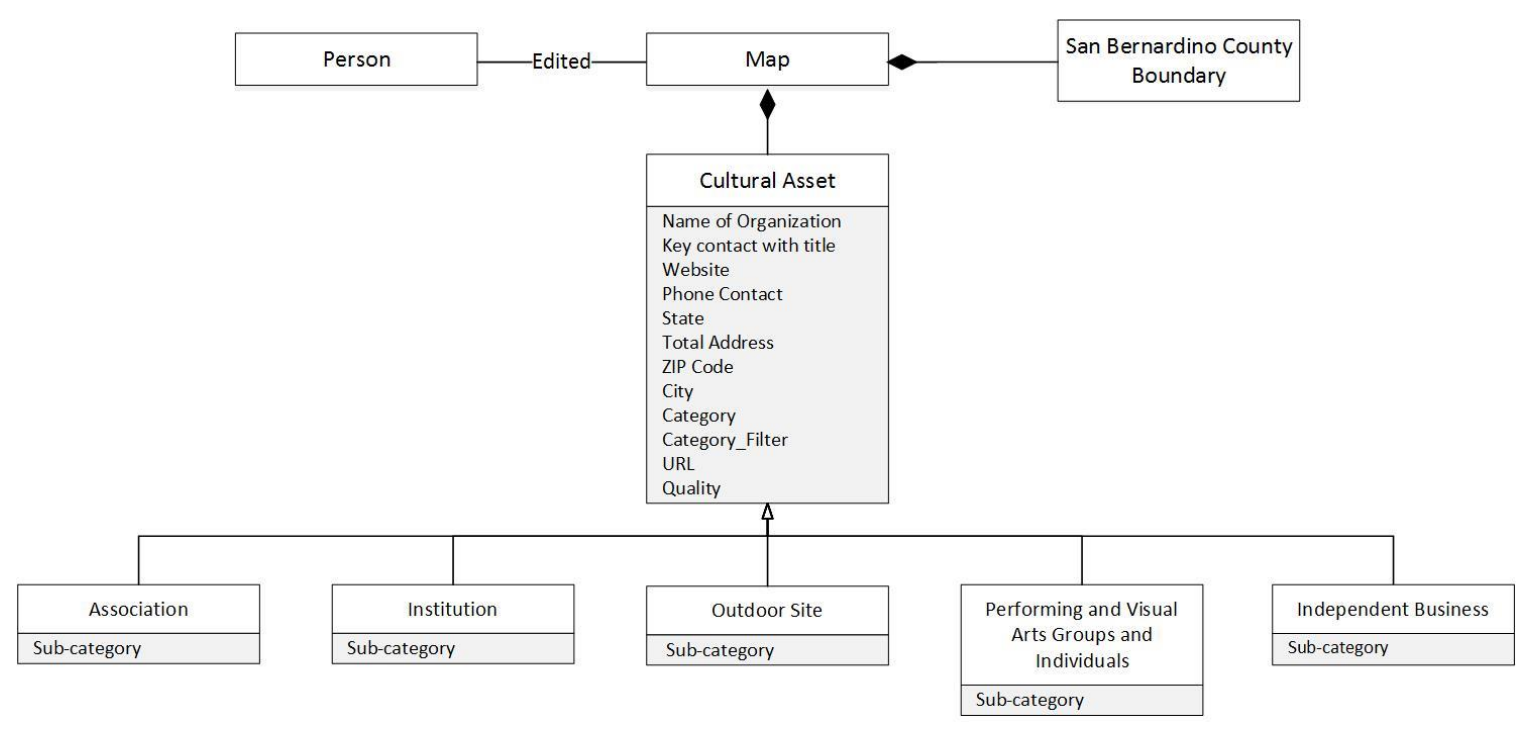

Figure 4-2: Logical Data Model

The database for this project contains only one feature class-Cultural Asset. This feature class is a set of vector objects that are represented by points as types of cultural assets. Five categories, along with their sub categories, were identified by the client to limit the diversity of cultural assets for the purpose of this project. Subtypes were required to represent different categories of the Cultural Asset feature class. In addition, each category has its own sub categories, to be used later as a domain. All of these categories inherit the same attributes of the Cultural Asset feature class.

The X-Ray add-in for ArcCatalog 10.3 was used to create the geodatabase layout. Figure 4-3 illustrates the subtypes, domains, and attributes of the Cultural Asset feature class that were used for this project. The figure also includes the data types for all the fields, which fields allow nulls, and the length of the fields 


\begin{tabular}{|c|c|c|c|c|c|c|}
\hline \multicolumn{4}{|c|}{$\begin{array}{l}\text {-- Simple feature class } \\
\text { Cultural_Asset_subtype }\end{array}$} & \multicolumn{3}{|c|}{$\begin{aligned} \text { Geometry } & \text { Point } \\
\text { Contains } \mathrm{M} \text { values } & \mathrm{No} \\
\text { Contains } \mathrm{Z} \text { values } & \mathrm{No}\end{aligned}$} \\
\hline Field name & Data type & $\begin{array}{l}\text { Allow } \\
\text { nulls }\end{array}$ & Default value & Domain & $\begin{array}{l}\text { Prec- } \\
\text { ision } \mathrm{S}\end{array}$ & cale Length \\
\hline OBJECTID & Object ID & & & & & \\
\hline Shape & Geometry & Yes & & & & \\
\hline Name_of_Organization & String & No & & & & 256 \\
\hline Key_contact_with_title & String & Yes & & & & 256 \\
\hline Website & String & Yes & & & & 256 \\
\hline Phone_Contact & String & Yes & & & & 256 \\
\hline Address & String & No & & & & 256 \\
\hline State & String & Yes & & & & 256 \\
\hline City & String & Yes & & & & 256 \\
\hline Sub_Category & String & Yes & & & & 256 \\
\hline url & String & Yes & & & & 256 \\
\hline Quality & String & Yes & $\mathrm{N}$ & Quality_Check & & 1 \\
\hline categories & Short integer & Yes & 1 & & 0 & \\
\hline ZIP & Long integer & Yes & & & 0 & \\
\hline Category_filter & String & Yes & & & & 50 \\
\hline
\end{tabular}

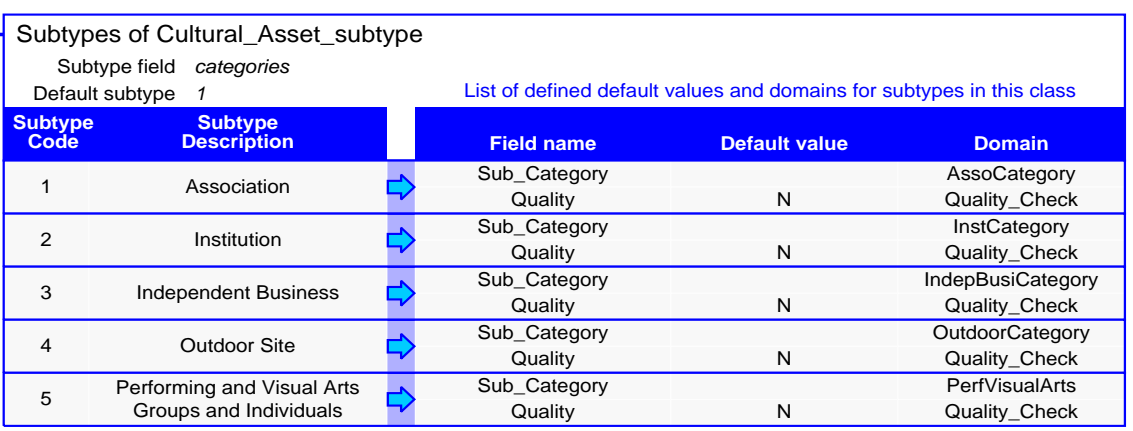

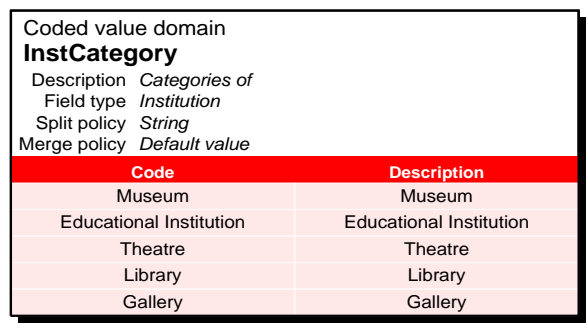

\begin{tabular}{|c|}
\hline Coded value domain \\
PerfVisualArts \\
Description Categories of \\
Field type Performing and \\
Split policy Visual Arts Groups \\
Merge policy and Individuals \\
\hline Code \\
\hline Dance Troupe \\
Theatre Troupe \\
Visual Artist \\
Musician \\
Orchestra \\
Symphony \\
\hline
\end{tabular}
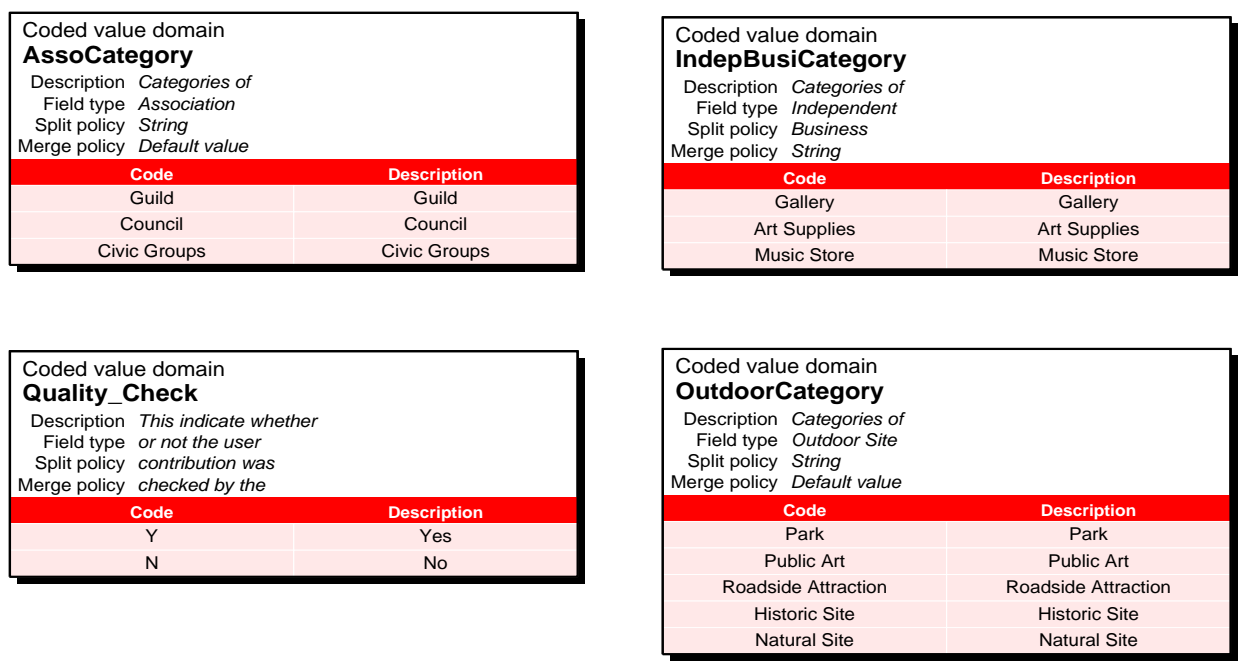

Figure 4-3: Geodatabase Representation for Cultural Asset Feature Class 


\subsection{Data Sources}

As mentioned in earlier sections of this report, the client has been working to identify San Bernardino County's cultural assets by crowdsourcing information through a Geoform template. This is commonly referred to as volunteered geographic information (VGI). It has been on the client's website since September 2015. The client provided the primary data for this project, which was derived in Excel spreadsheet format from the Geoform. She also provided another Excel spreadsheet throughout the development of the project. Access to an ArcGIS Online organizational account, with the necessary privileges for creating and publishing data, was provided by the client. The account was also used to access the client's feature service of San Bernardino County and the World Topographic Map service of ArcGIS Online as a basemap of the application.

\subsection{Data Scrubbing and Loading}

Once a dataset was delivered from the client, it needed to be inspected to ensure its quality. In many cases, the data eventually needed to be cleaned, converted, and geocoded in order to ensure a smooth loading process and to meet the schema specifications, and to optimize the performance of the web application.

The first step was to clean the data and determine the required fields that needed to be implemented in the database. The Cultural Asset feature class, which was provided by the client in Microsoft Excel spreadsheets, included all the information needed for this project. Excel was used to visually review and organize the data; clean up minor issues in the data; and after the data were cleaned and organized, they were exported into a comma-separated value (CSV) format, which was then easily imported to ArcGIS Online. The cleaning involved finding a number of specific types of mistakes, such as 
duplicate records and missing addresses, and adjusting the format of the fields. A SubCategory field was added to the original table to be used as a domain in order to narrow the choice of assets for a particular category.

The second step was to develop the geodatabase in advance with the subtypes, domains, and attributes of the Cultural Asset feature class before importing the clean data into the production database. ArcCatalog 10.3 was used to build the production geodatabase schema. The exported CSV file was imported into ArcGIS Online to geocode addresses using World Geocoding Service from ArcGIS Online. After the geocoding process was done, the data was downloaded from ArcGIS Online to ArcGIS 10.3 for Desktop to migrate the clean geocoded data into the production geodatabase. It should be noted that, before migrating the data, a sample representing a subset of the database was visually inspected to ensure the quality of the data.

\subsection{Summary}

This chapter discussed the conceptual and logical data models that were implemented in this project. They were built to facilitate the development process of the desired database and to ensure adequate representation of the required features inside the geodatabase. The chapter started by identifying the entities of the client's problem. The chapter went on to describe how the data to be included in the GIS database was organized into logical sets of features with attributes needed to build the desired model that will support the client's functions. This chapter also discussed the process for preparing the production geodatabase, which involved data sources, data scrubbing, geocoding, and loading. 


\section{Chapter 5 - Implementation}

This chapter describes the two components that were developed to meet the client's

needs. A file geodatabase, which was used to store, organize and edit the datasets as a file folder, will be discussed in Section 5.1. A web map application, which was used for viewing, editing and configuring various functions, will be discussed in Section 5.2. This section also discusses the methods that were used to publish the feature service using the client's ArcGIS Online organizational account and enable the editing capabilities of the feature on the web map.

\subsection{Database Development}

Building the production database was the first step in the implementation of this project. The database was built based on the conceptual and the logical data model that was discussed earlier in Chapter 4. In order to enter spatial and attribute data into the ArcGIS environment, the data structure of the database needed to be put in place.

There are different ways to organize data inside a GIS. Raster data structures and vector data structures offer the two most common ways currently used by different types of GIS. Raster data structures are based on a grid, or cellular, system of organization. Vector data structures are not tied to a cell system of organization. They are based on coordinates that are stored together in such a way that spatial objects can be described from the points, lines and polygons that makes up those coordinates. For the purpose of this project, only vector data structures were used in the development process of the production database. 


\subsubsection{Creating a Cultural Asset Geodatabase}

Before the actual creation of the database specifications for the content and structure, the software needed to be selected. The project was developed with Esri software because the client has an ArcGIS Online organizational account. Once the selection of software was made and the logical model was created, they were used to create the geodatabase in ArcCatalog 10.3. There are three types of geodatabase offered by Esri: the personal geodatabase, the file geodatabase, and the large ArcSDE geodatabase. Each one of them supports a range of users, platforms, size limits and storage formats. In respect to the client's requirements, it was found that the file geodatabase would be best. The file geodatabase stores datasets in files or a folder. It organizes real-world features by using a collection of feature classes, tables, and raster datasets. This project deals with vector data pertaining to cultural assets, which were represented as points. The ArcCatalog 10.3 platform was used to build the file geodatabase, with one feature class that contains all the information needed in the logical model. ArcCatalog was also used to project the data into Web Mercator Auxiliary Sphere coordinate system. This was an important step because the data had to be displayed correctly in the web application while it used other services such as the Esri basemap.

\subsubsection{Maintaining Database Integrity Using Subtypes and Domains}

To meet the client's specifications for this project, subtypes were needed to categorize different types of cultural assets so that users could edit them individually. Each of these subtypes was associated with default values and a specific domain list to narrow the choice of values for the sub categories. Subtypes and domains provided a method for enforcing data integrity and controlling the feature class behavioral characteristics. In this 
project, the Cultural Asset feature class was categorized into five subtypes: Association, Institution, Independent Business, Outdoor Site, and Performing and Visual Arts Groups and Individuals. In order to create a subtype in ArcCatalog, an integer field had to be created. A subtype field, Categories, was created to store the subtype codes. Figure 5-1 shows the subtype code for the Cultural Asset feature class, including the Default Values and Domains settings for the Association subtype.

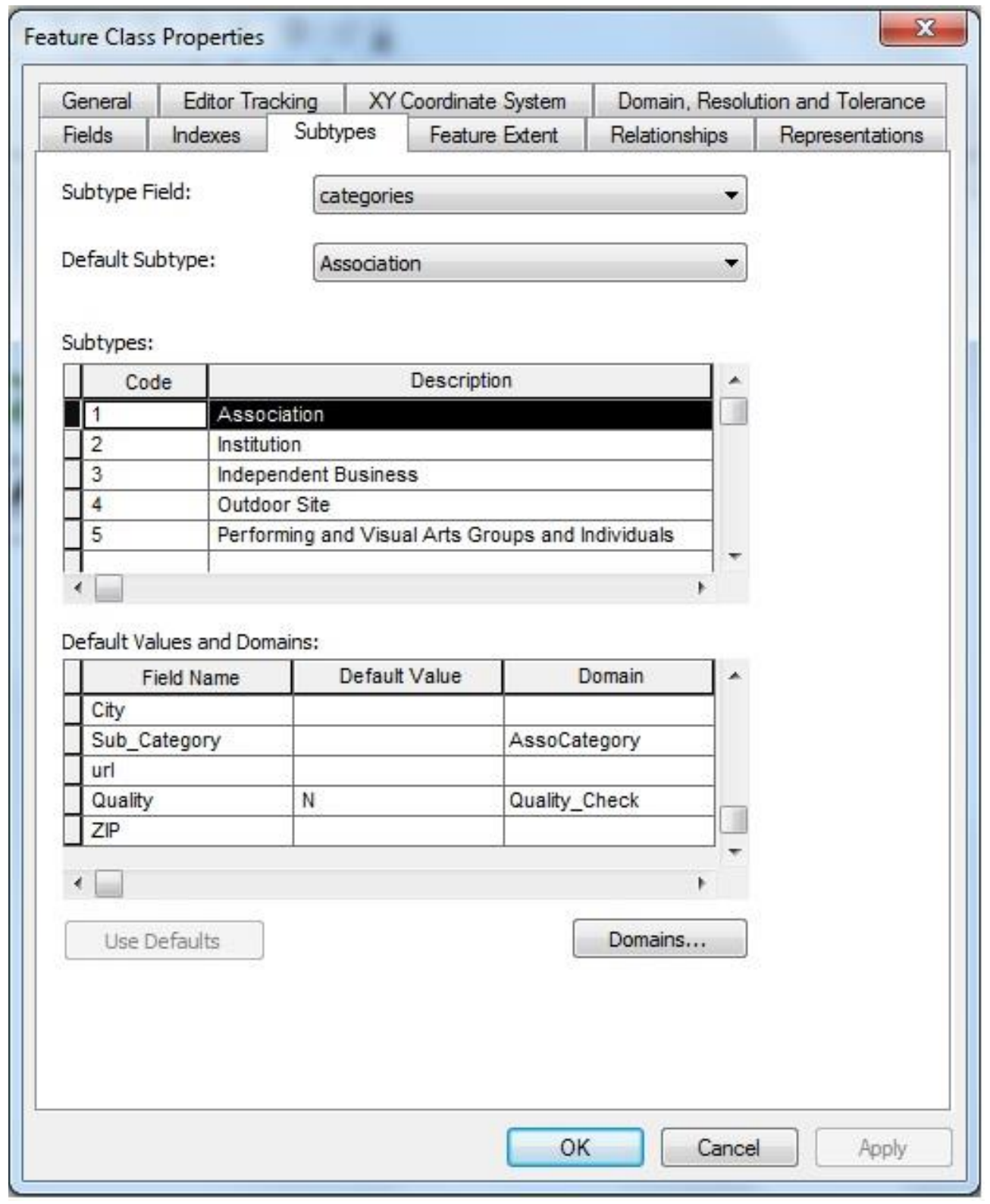

Figure 5-1: Association Subtype 
Domains play an important role in attribute data validation in the geodatabase. They define a range of numeric values or a coded of text value that can be used to constrain the legal values allowed in any attribute fields of feature class. One domain can also be associated with multiple fields of the same feature class or subtype. This will help the client to collect high quality data and provide an easy way of editing for the end user. Six coded-value domains were created to meet the project goals. Five of these domains represent different sub categories for each cultural asset subtype (Table 5-1).

Table 5-1 Domain List for each Subtype

\begin{tabular}{|l|l|l|l|l|}
\hline Outdoor Site & Institution & Association & $\begin{array}{c}\text { Performing and Visual } \\
\text { Arts Groups and } \\
\text { Individuals }\end{array}$ & $\begin{array}{l}\text { Independent } \\
\text { Business }\end{array}$ \\
\hline Park & Museum & Guild & Dance Troupe & Gallery \\
\hline Public Art & $\begin{array}{l}\text { Educational } \\
\text { Institution }\end{array}$ & Council & Theatre Troupe & Art Supplies \\
\hline $\begin{array}{l}\text { Roadside } \\
\text { Attraction }\end{array}$ & Theatre & Civic Groups & Visual Artist & Music Store \\
\hline Historic Site & Library & & Musician & \\
\hline Natural Site & Gallery & & Orchestra & \\
\hline & & & Symphony & \\
\hline
\end{tabular}

The values in each field are chosen from a drop-down list. For example, a codedvalue domain for the Sub_Category field in the Association subtype was constrained to a list of values such as Guild, Council and Civic Groups. The actual value of the codedvalue domain was stored in the database with an alias that describes what that value really means. The last domain was used for quality control, and it was applied for each subtype. It was used by the client to verify the quality of user-contributed data on the web application and to ensure that the content posted is relevant, credible and not offensive in 
context. This field was set up as a domain with two values: yes and no. It has a default value of "N". So whenever the user adds a new cultural asset to the web map application, it will not be available on the map until the client validates the edit.

\subsection{Web Application Development}

This section discusses the process that was used in the web application development, which involved map document preparation, publishing feature services, and creating and configuring the web map, and developing the web map application.

\subsubsection{Map Preparation}

After migrating the geocodes and the clean data into the production geodatabase, ArcMap 10.3 was used to symbolize different subtypes within the Cultural Asset feature class and to author the web map that would eventually be published to the client's ArcGIS Online organizational account. The map document (Figure 5-2) includes the five subtypes of the Cultural Asset feature class: Association, Institution, Outdoor Site, Independent Business, and Performing and Visual Arts Groups and Individuals. Each subtype was symbolized based on the client's wishes so that it could be edited individually by the end user via the web map. By doing so, the map was ready to be published to the client's ArcGIS Online account and hosted on the ArcGIS Online infrastructure. 


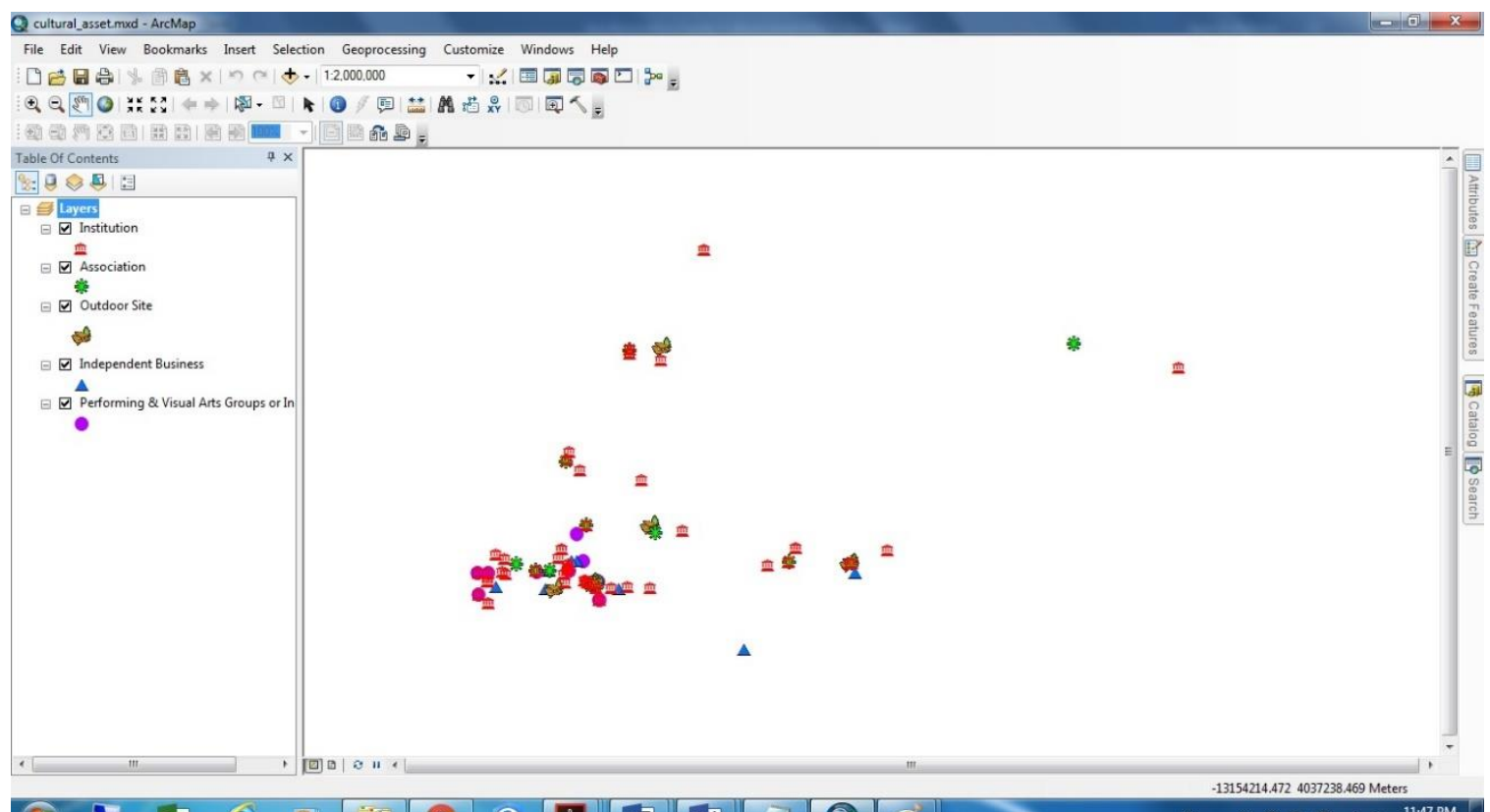

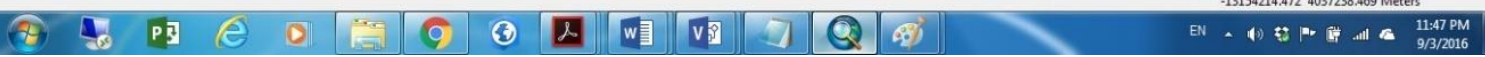

Figure 5-2: Map Document to Be Published

\subsubsection{Publishing Feature Services}

Once the map was authorized on the ArcMap platform, it needed to be published and hosted on the client's ArcGIS Online organizational account. However, ArcGIS Online for organizational accounts only allow users to publish two type of services: tiled map and feature service. Considering the goal of the web map application, which is to allow citizens to collect, locate and visualize their county's cultural assets, the feature service was selected. The feature service would allow the service to be editable, added to, and synchronized in the geodatabase remotely via a web GIS client application (Fu \& Sun, 2011). The MXD file for this project contains only the Cultural Asset feature class, and it would be published as a feature service.

The process of publishing feature service into the client's ArcGIS Online organizational account consisted of three steps. First, users must provide their ArcGIS organization's URL and then sign in with publisher or administrator privileges from 
ArcMap in order to publish the feature services. Figure 5-3 shows the two login panels provided by the Sign In button through the file menu in ArcMap.
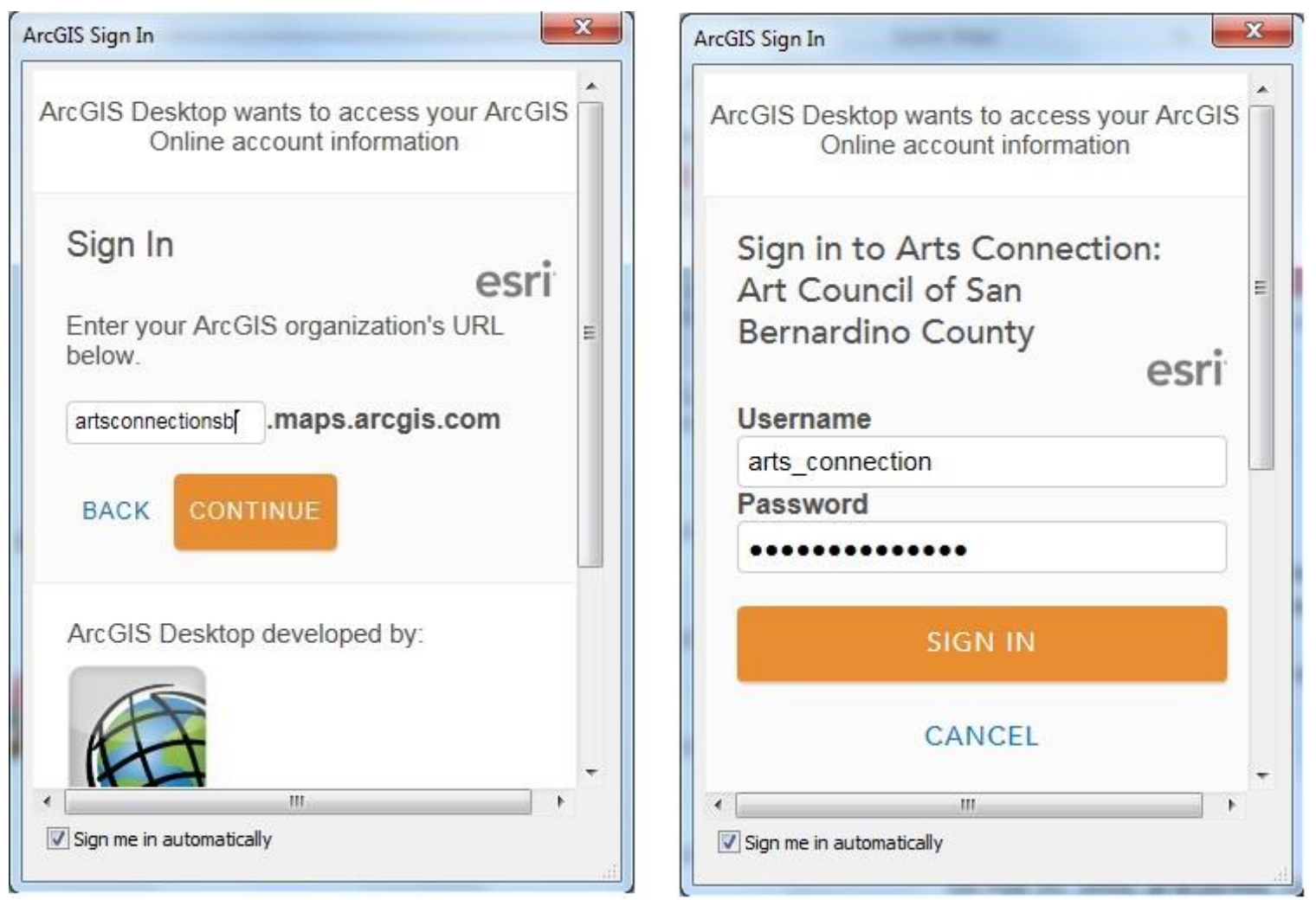

Figure 5-3: The ArcGIS Online for Organizations Login through ArcMap

Second, the map needed to be shared as a service through ArcMap with all the capabilities that would meet the client's requirements. Figure 5-4 shows the capabilities and the operations that end users can perform when they access the service via the web application. 


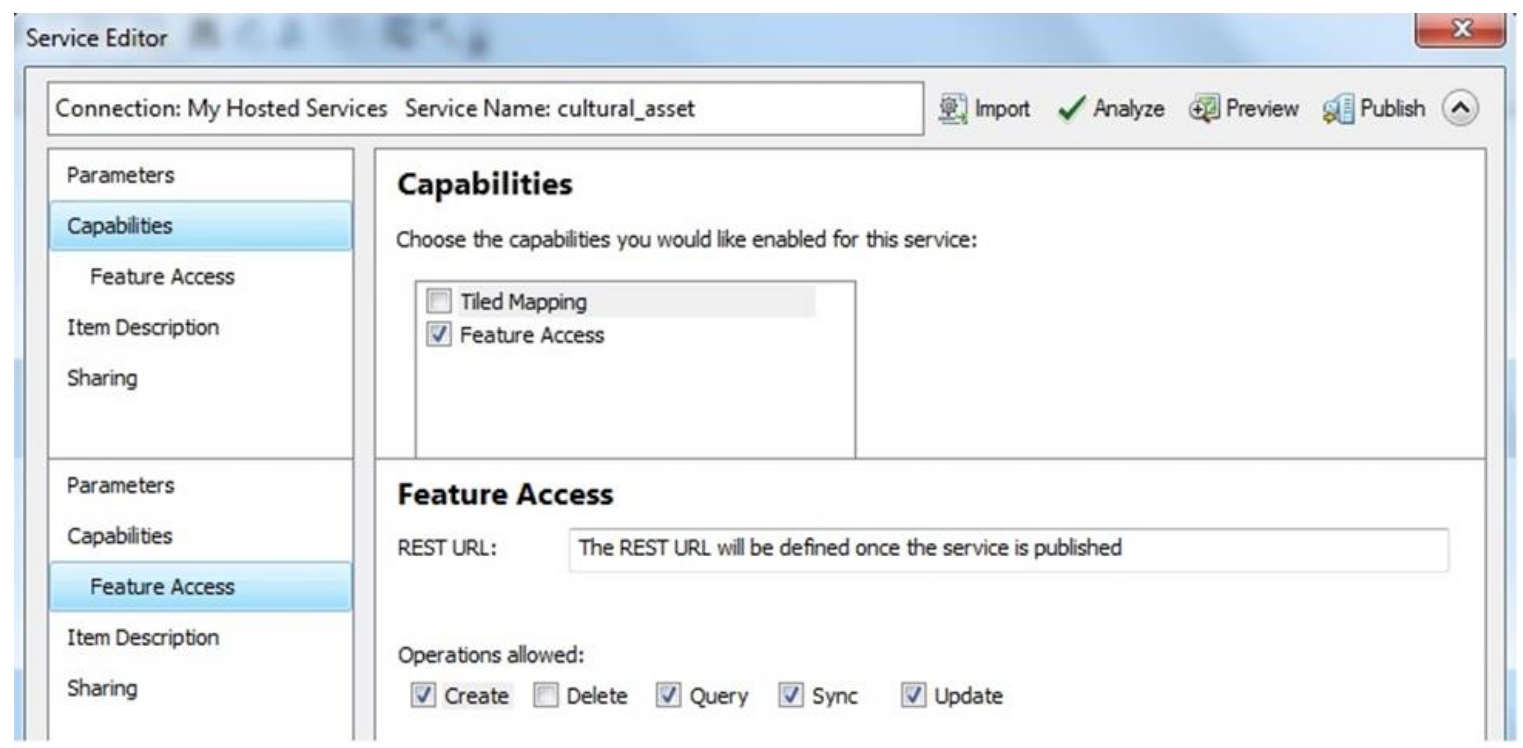

Figure 5-4: Feature Service Settings

Third, the MXD file needed to be analyzed to look for any errors or warnings before publishing the map with the layer as a feature service. Clicking the Publish button in the Service Editor window will publish the service in ArcGIS Online.

After the feature service was successfully published, it could be explored in the ArcGIS REST Services Directory (Figure 5-5), and the attachment capability for the feature service could be enabled. The client required allowing users to contribute relevant attachment with information, such as brochures about upcoming events. It should be noted that the boundary of San Bernardino County was already available as a feature service via the client's organizational account. 


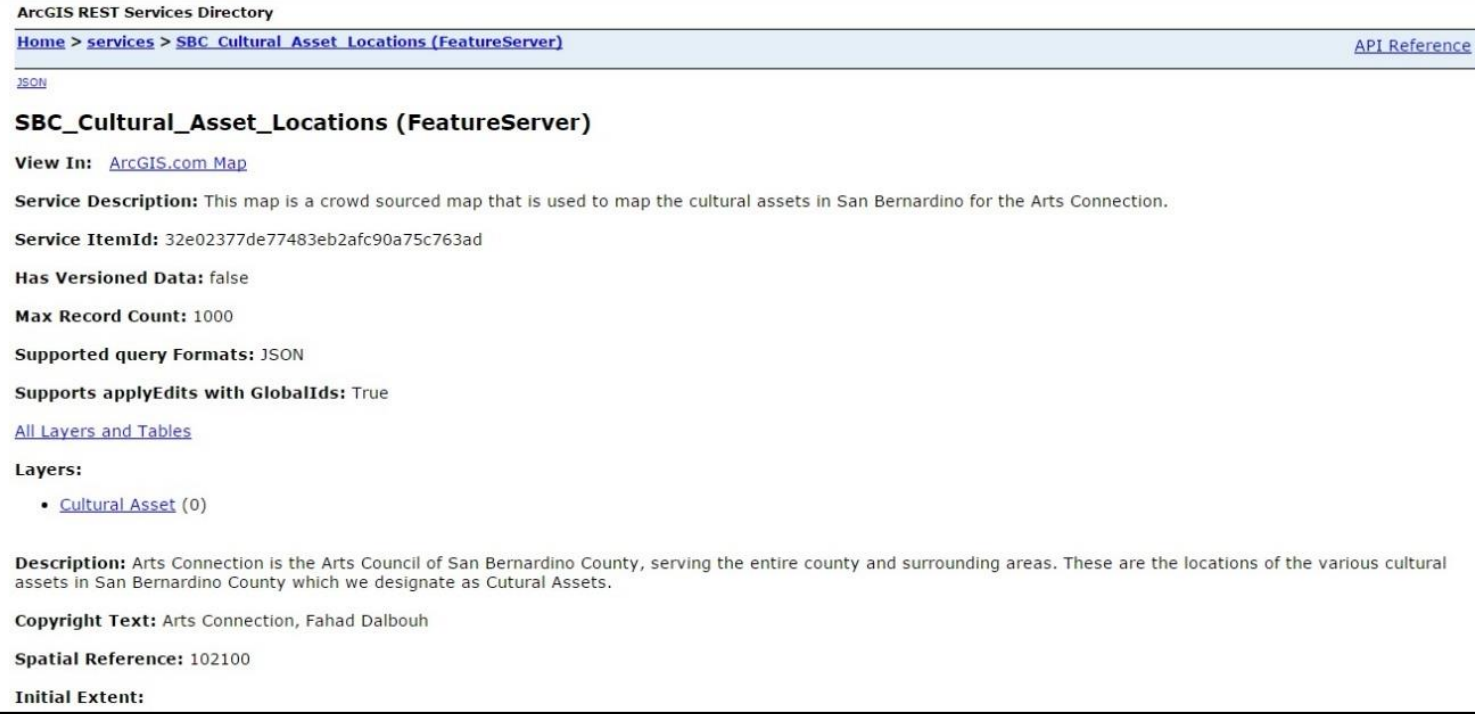

Figure 5-5: The ArcGIS REST Services Directory

\subsubsection{Creating and Configuring the Web Map}

Once the feature service was published to the client's organizational account, the web map needed to be created and the pop-ups needed to be configured on the operational layers. The main two components of this web map are basemaps and operational layers. The topographic basemap provided by ArcGIS Online was used to display the cultural assets' locations. There were two operational layers for this project: one for cultural assets and the other for the boundary of San Bernardino County. These layers were drawn on top of the basemap, and end users have the ability to view and edit only the Cultural Asset layer. The feature service in ArcGIS Online gives users the option of opening the layer in map viewer. The map viewer interface looks similar to the ArcMap platform but has fewer capabilities. The map viewer was used to configure the pop-ups, add the Boundary of San Bernardino County layer from the client's account, and save the map as a web map. The map viewer was also used to filter the Quality field in the Cultural Asset 
layer. By setting the expression of the Quality field to display the value of "Y", the end user cannot directly post edits to the web application until the client validates the edits.

\subsubsection{Developing the Web Application}

Web App Builder for ArcGIS (WABA) was used to build the user interface (UI) and the functionality of the web application. Web App Builder provides the ability to rapidly build web apps, with or without programming, and deliver specific online mapping applications based on the online GIS content. WABA has a developer edition as well as an integrated edition within ArcGIS Online. The developer edition provides more control in building and customizing widgets or tools but requires downloading and web hosting, unlike the integrated edition, which is hosted in ArcGIS Online and does not require downloading ( $\mathrm{Fu}, 2015)$.

Considering the client's requirements and the availability of the resources, the integrated edition was the appropriate choice for developing the web map application. WABA provides a workflow using tabs including Map, Attribute, Theme, and Widget (Figure 5-6). The Map tab was used to select the web map that would be displayed for the end user and to define the extent of the area. The Attribute tab was used to configure the web app's banner (i.e., title, logo and links).

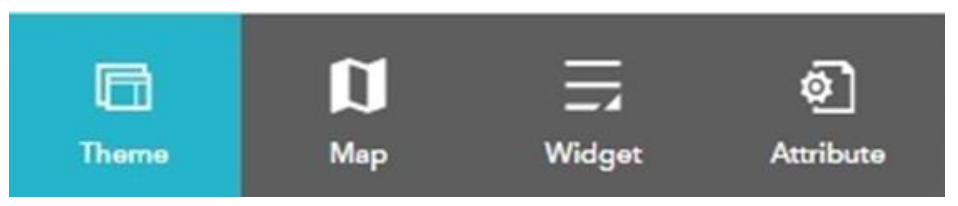

\section{Figure 5-6: The Workflow Tabs in Web AppBuilder for ArcGIS}

Theme and Widget tabs are the most important tabs in WABA because they define the UI and the functions of the web application, respectively. There are a wide range of preconfigured widgets and themes that can be utilized without programming (Figure 5-7). 


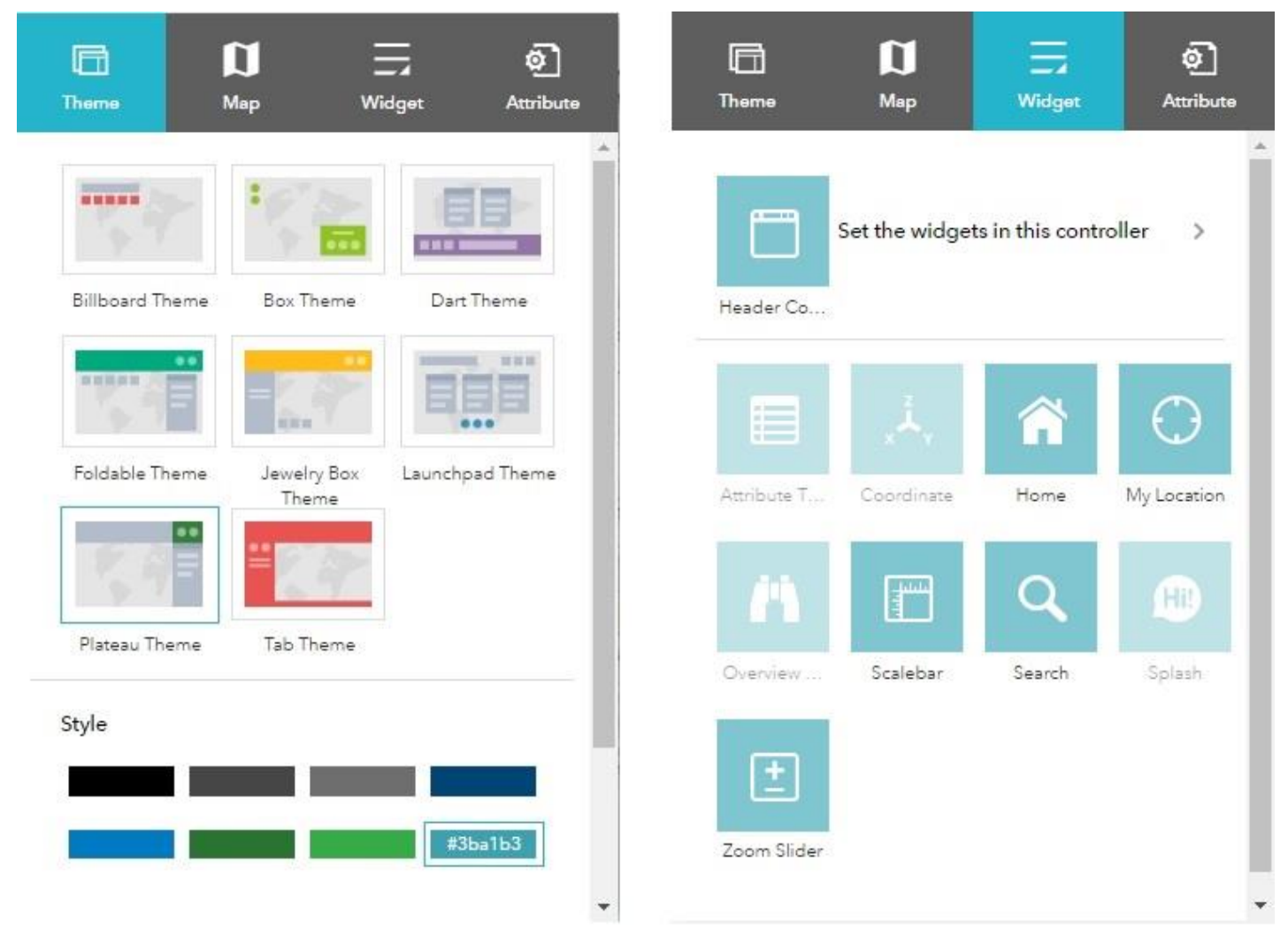

Figure 5-7: Preconfigured Widgets and Themes in Web AppBuilder for ArcGIS

Plateau Theme was selected from a diverse collection of preconfigured templates to represent the look and feel of the application. Different widgets were configured for this web map application to meet the client's needs. These widgets included Home, My Location, Scale Bar, Search, and Zoom Slider on the left side of the interface, and Legend, Basemap Gallery, About the Map, Filter, Near Me, Editor, Share, Print, and Chart on the right side of the interface. All of these widgets are discussed in Chapter 3, Section 3.2.2-Functional Requirements.

The Smart Editor widget was taking as an example of configuration widget among several widgets that are available within WABA. First of all, there are two types of editing widgets that can be utilized in WABA: Edit and Smart Editor. The Smart Editor widget extends the Edit widget with more capabilities and features. For example, the 
ability to set up mandatory fields, preset field values, edit a series of features, and more. Figure 5-8 shows the configuration window of the Smart Editor widget.

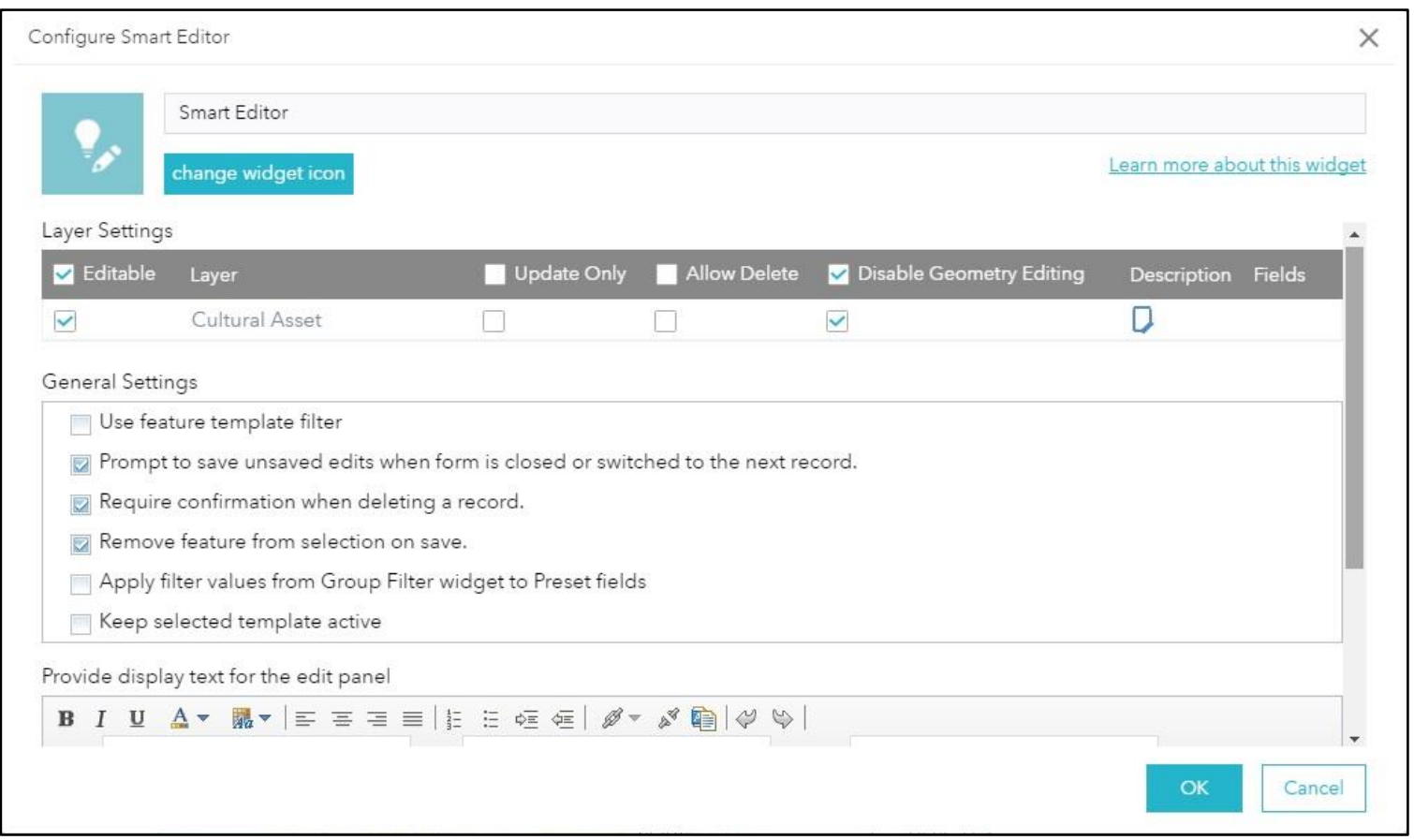

\section{Figure 5-8: The Smart Editor Configuration Window}

From this window, the user can control the actions and capabilities for each layer on the map. For example, here the user determines whether a layer is to be editable, updated or deleted. Moreover, the user can choose to disable, hide or require a field on the web map application (Figure 5-9). 
Use the Preset column to allow the user to enter a value prior to creating a new feature. Use the Actions edit button to activate Smart Attributes on a layer. The Smart Attributes can require, hide or disable a field based on values in other fields.

\begin{tabular}{llllll}
\hline & Displ... & $\square$ Editable & $\square$ Preset & Name & Alias \\
$*$ & $\square$ & $\square$ & Name_of_Organization & Name of Organization \\
$\square$ & $\square$ & $\square$ & Key_contact_with_title & Key Contact with Title \\
$\square$ & $\square$ & $\square$ & Phone_Contact & Phone Contact \\
$\square$ & $\square$ & $\square$ & Address & Address \\
$\square$ & $\square$ & $\square$ & City & City \\
$\square$ & $\square$ & $\square$ & State & State \\
$\square$ & $\square$ & $\square$ & ZIP & ZIP Code \\
$\square$ & $\square$ & $\square$ & categories & Category \\
$\square$ & $\square$ & $\square$ & Sub_Category & Sub Category \\
* is a required field. If you uncheck Display for this field, and the edit template does not populate that field value, you will not be able to save a \\
new record.
\end{tabular}

\section{Figure 5-9: Setup Required fields}

The rest of widgets have a similar configurable workflow with specific options, and they are easy to configure. Some widgets depend on capabilities that have been set before publishing the feature service to the ArcGIS Online. For example, if the feature service was set up to be updated only, the widget will not allow the user to create or delete.

\subsection{Summary}

This chapter discussed the major implementation tasks that were undertaken to deliver the desired results. It started by developing the physical geodatabase along with additional geodatabase functionalities such as subtypes and domains. The chapter went on to describe the creation of the web application for the Cultural Asset Mapping Project, from map preparation to publishing the feature service and the development of the web application using WABA (integrated edition). The chapter also covered the process of enabling some of the different types of operations and properties on the feature service so that the end user can use them on the web application. 



\section{Chapter 6 - Use Cases and Results}

This chapter begins with case studies outlining the use of the application and the second part goes on the analysis results that were performed to address different types of questions. This chapter presents two use cases: one for a resident who would like to find out what cultural assets are available within their neighborhood (Section 6.1); the second use case is for an artist who is interested in being recognized as an asset and part of a larger group (Section 6.2). Section 6.3 discusses the different types of analyses that were conducted to examine the data and the patterns.

\subsection{Browsing the Cultural Assets in San Bernardino County}

Suppose a resident of San Bernardino County has a passion for cultural resources and is interested in knowing where to find the most valuable assets to the local people. The resident would use this web application to learn more about them.

Once the application is launched, the resident sees a topographic map of San Bernardino County and the distribution of cultural assets along with the legend on the right (Figure 6-1). The web map application offers several additional tools for the resident. These tools are located in a ribbon on the top right side of the application for easy access and use. As a resident, the user can search on the map by the name of an organization or the address of a cultural asset's location through a search box. 


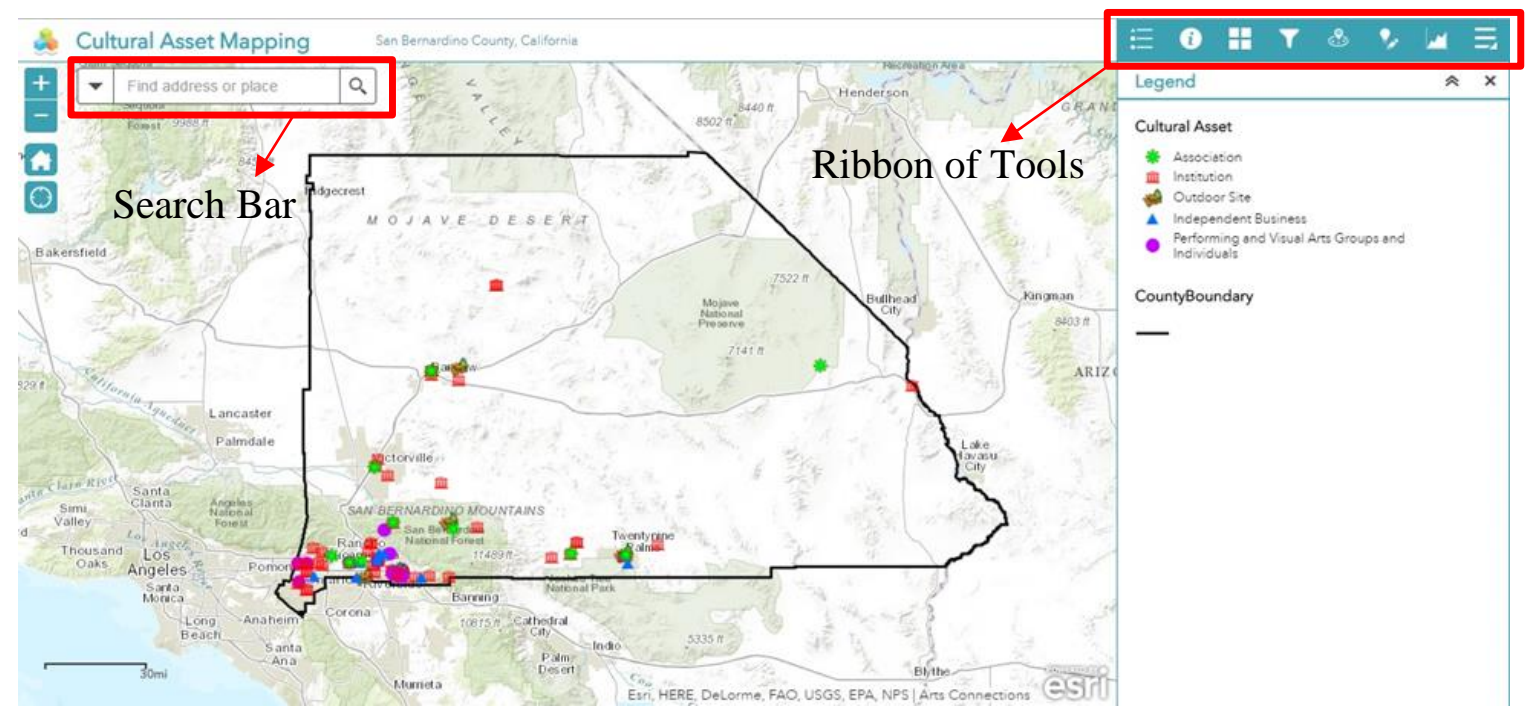

Figure 6-1: Initial Application View

To learn about the map, the resident can click the About icon ii in the ribbon to display the contents of the application. The resident can also switch the topographic map to satellite imagery using the Basemap Gallery widget $\#$. A resident who wants to find out what cultural assets are available in a specific city, or to search for a specific type of cultural asset within a city, can use the Filter widget to filter the map using a drop-down list for the city and the category of cultural asset (Figure 6-2). It has to be noted that the map will only display what has been collected from different users and that it may not include all cultural assets or the cities where they exist. 


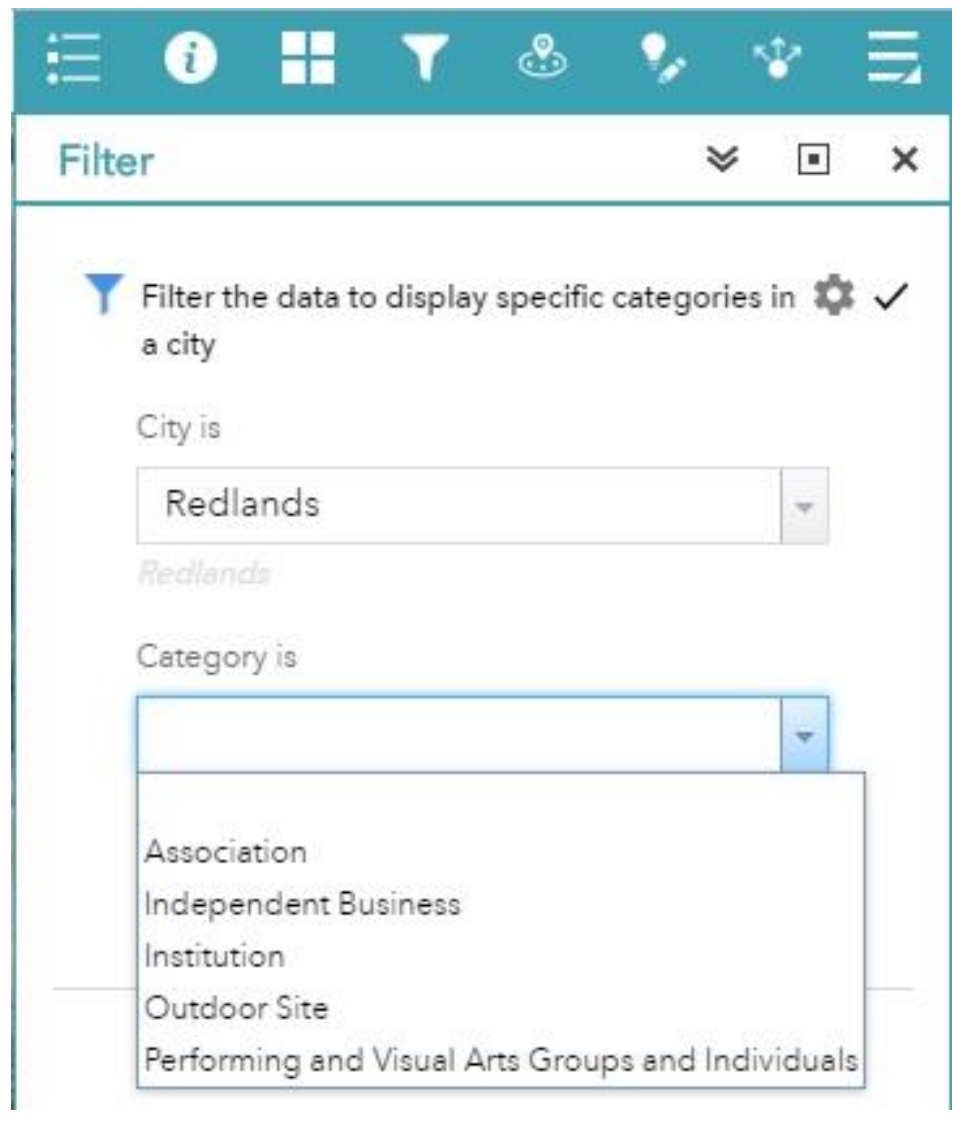

Figure 6-2: Filter Widget Based on the City and Category of the Cultural Asset

In addition, the resident has the ability to look up what cultural assets are within a buffer of a specified address or location and be able to get directions to them. The default and maximum distance of the buffer was set to 1 up to 20 miles. The buffer slider can be adjusted to the desired value by the user. For example, the resident may want to know the cultural assets within 5 miles from his home. He can first drop a pin on the map at his residence or enter his home address to get the location. Then he can adjust the buffer slider to 5 miles because the default was 1 mile. A list of cultural assets found within the given address buffer was displayed on the panel as well as the distance needed (Figure 63). Each cultural asset in the panel can be accessed for further information and direction. 
It is important to enable the routing in the application settings of the ArcGIS Online to be able to provide driving directions for the user.

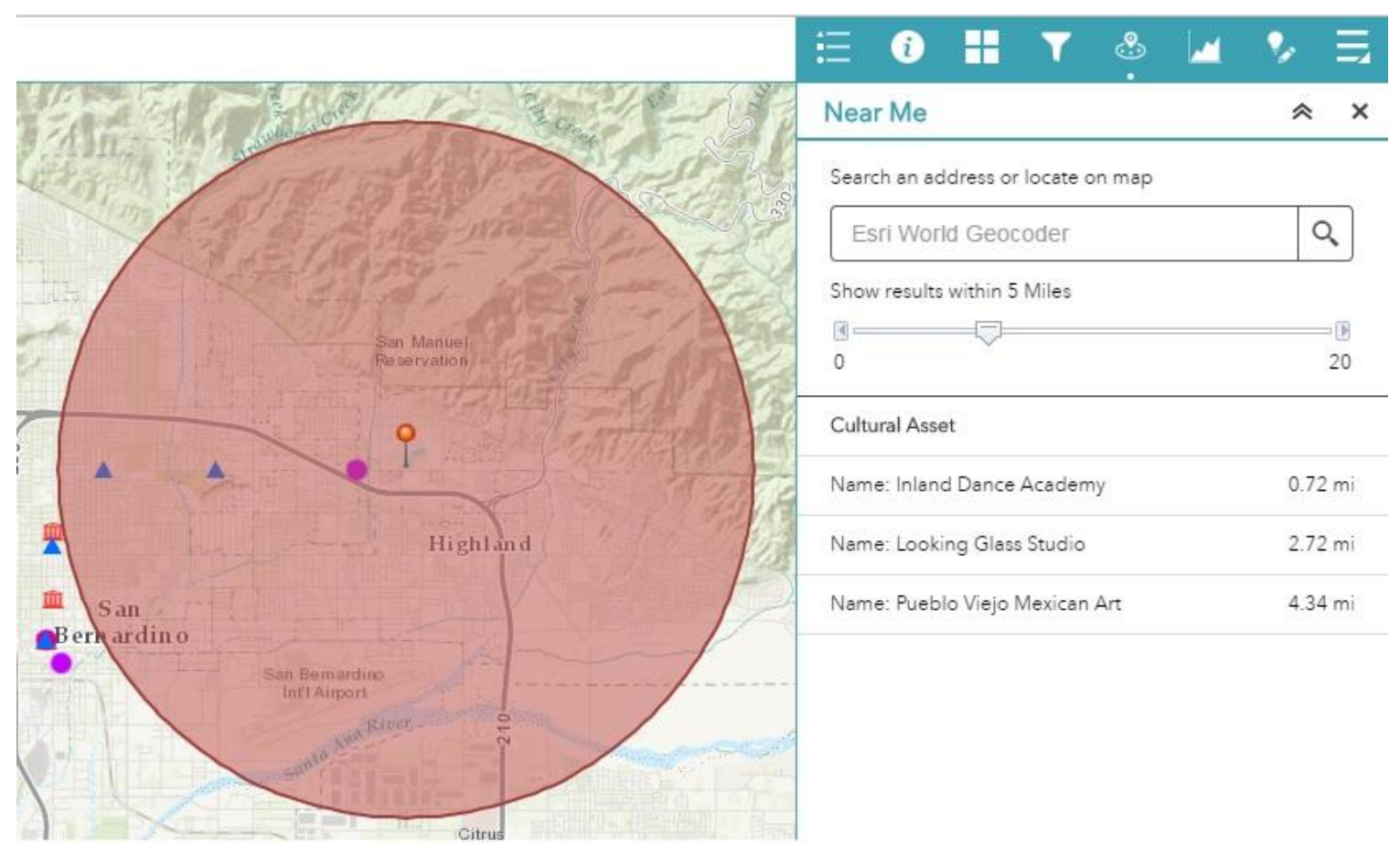

\section{Figure 6-3: A List of Cultural Assets that was Located within 5 Miles from the Resident's Home}

It is also important to note that the cultural assets in the output are selected based on the Euclidean distance, instead of the network distance. However, the directions listed on the right output panel are based on the network distance. Therefore, it is possible that it takes more distance to get to the selected culture assets. Figure 6-4 shows an example of the problem. 

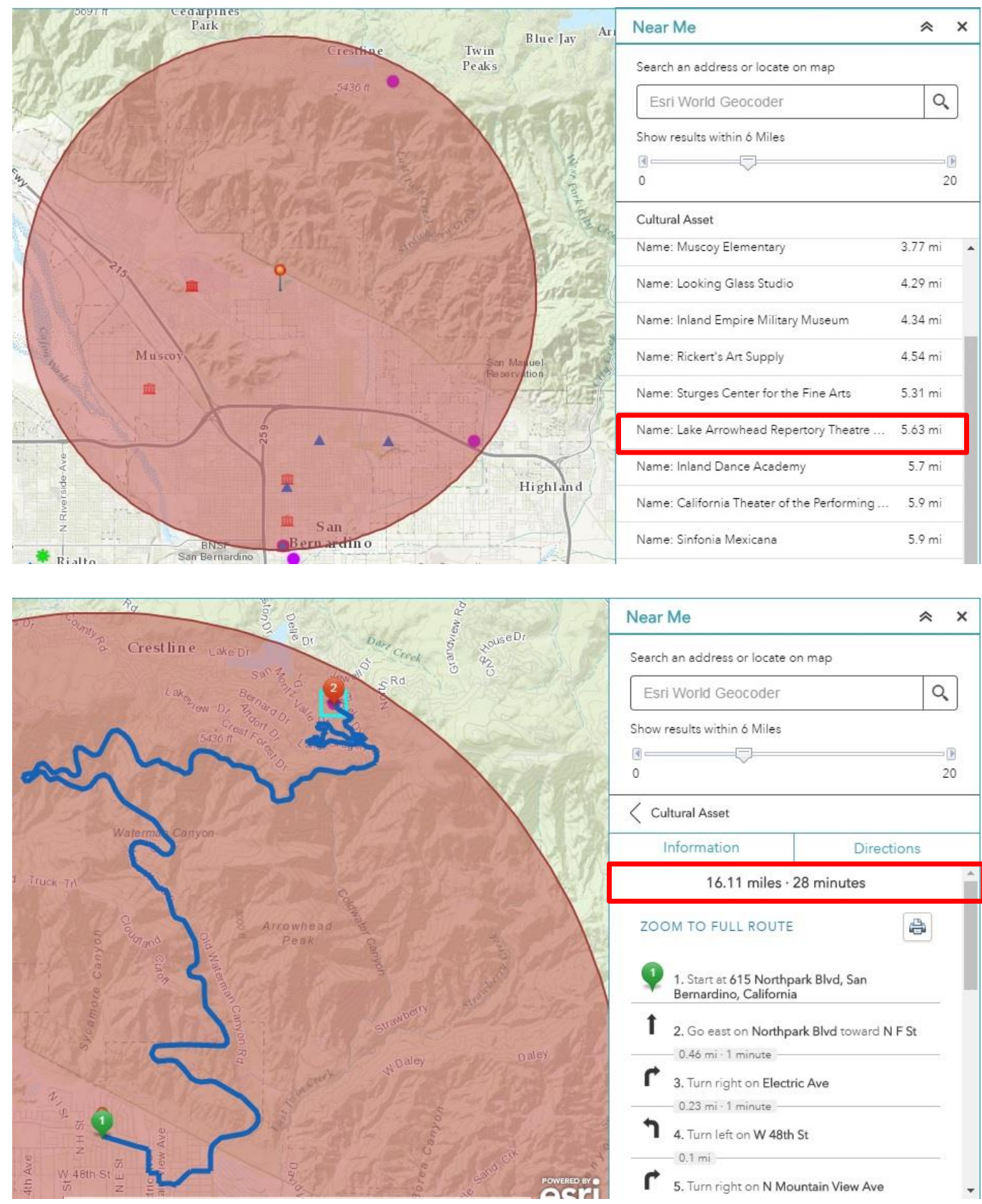

Figure 6-4: Problem of Incorrect Distance Information

The resident can also view chart information based on the total feature counts for each category of cultural assets within the current extent or a given area. For example, the resident wants to view chart information in a specific area that he defined by drawing a 
graphic on the map (Figure 6-4). Hovering over each category in the column bar chart displays the total number of assets, and the corresponding asset highlights on the map.

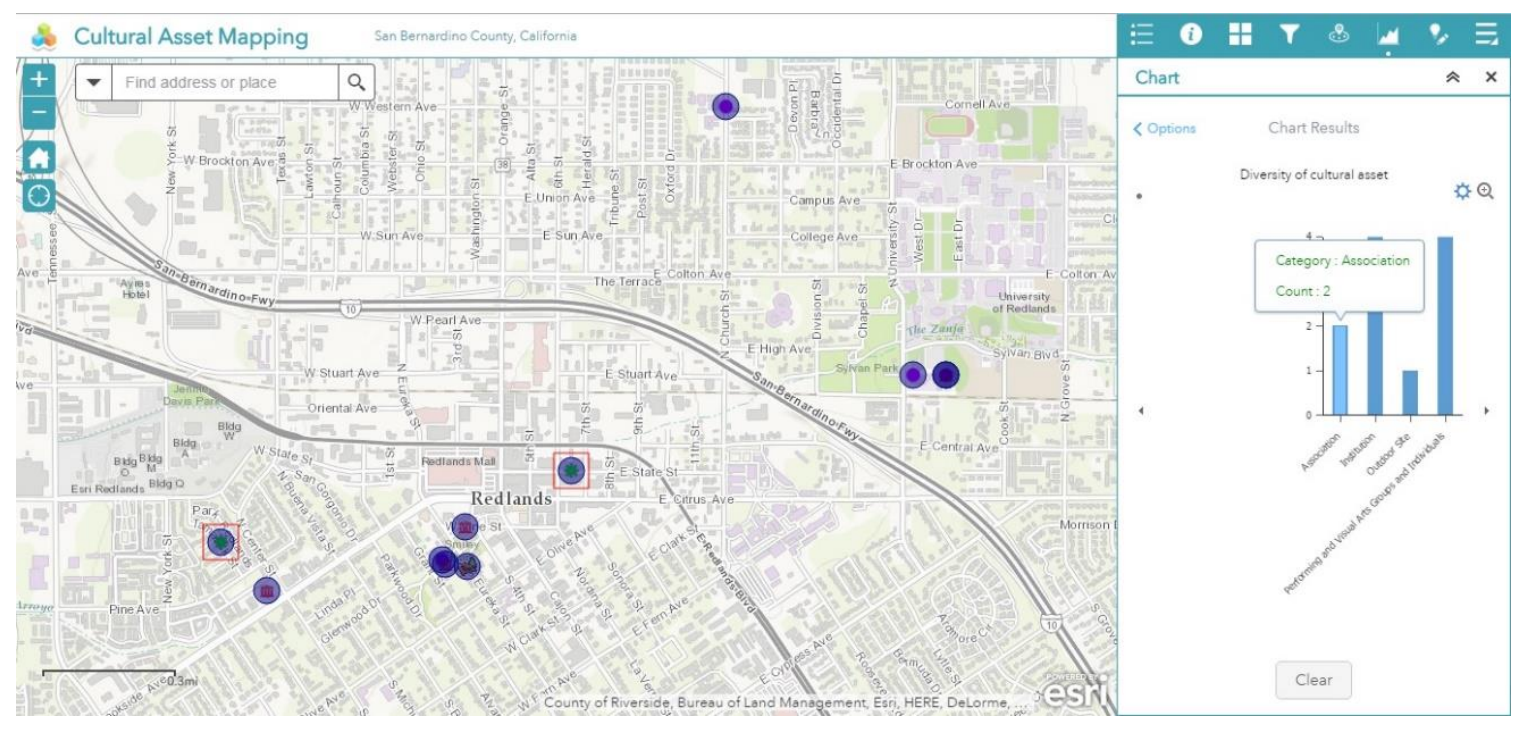

Figure 6-5: Performing Chart Widget Capability

Furthermore, the resident can easily share the web map application with others by embedding it in a blog or website or posting it to social media such as Twitter and Facebook. Also, the user has the ability to print the current map extent. Finally, the user can click any of the cultural asset icons on the map to view information about the asset.

\subsection{Editing the Cultural Asset Dataset}

Now, Arts Connection, the arts council of San Bernardino County, would like to engage artists in developing collaborative projects and, most importantly, facilitate the process of collecting their locations. This will serve their communities and provide more options for accessing the arts. Suppose an artist, who has an art studio in his house, has been making art for a long time, and he comes across this web map application. He might be willing to provide access for the public to his studio but hasn't known how to reach more people and be recognized as a cultural asset. This application gives artists the ability to add their 
location to this application so that it can be displayed on the map after the client verifies these edits. Once the web application is launched, the artist would click the Editor icon on the top right side of the menu bar (highlighted in red) and then follow the steps on how to add a new asset to the application (Figure 6-6).

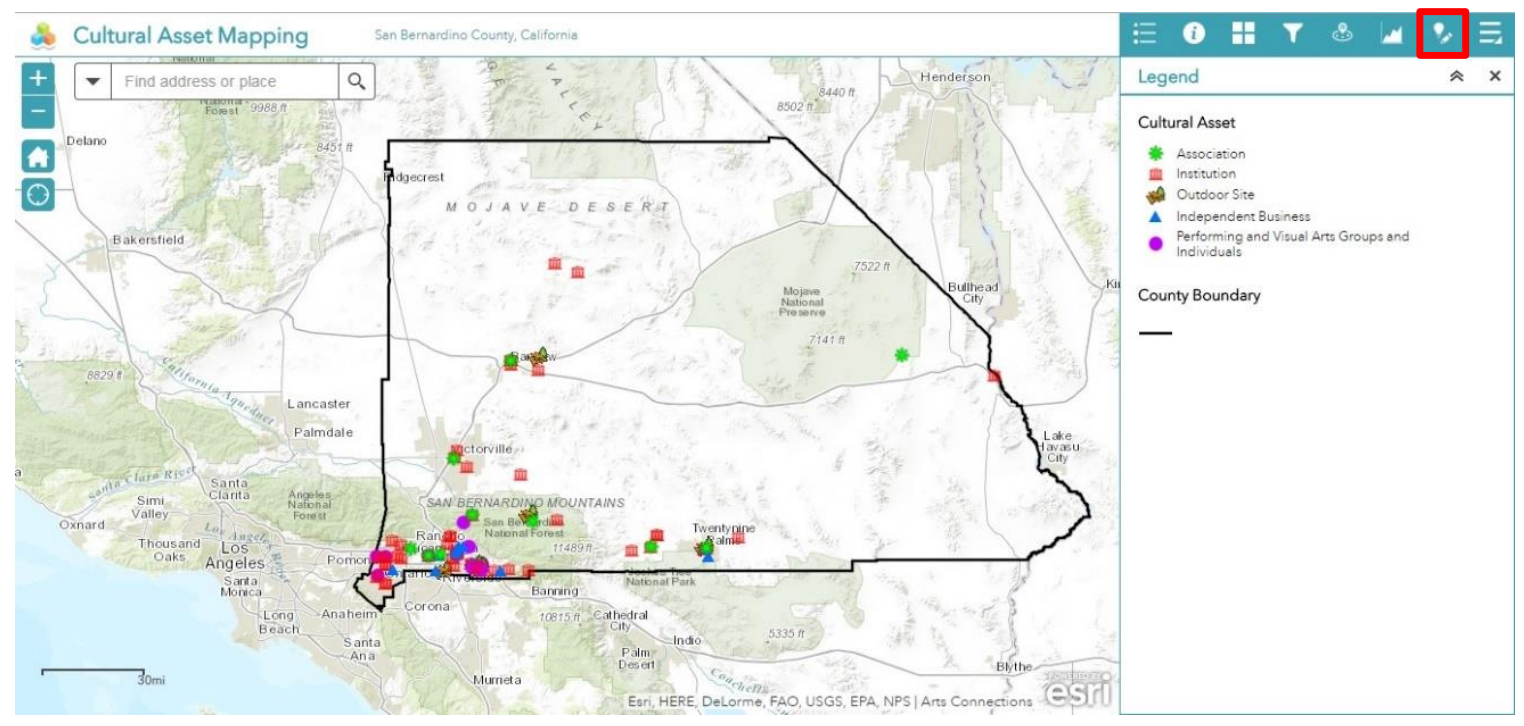

\section{Figure 6-6: Editor Widget with Editing Enabled for the Cultural Asset}

The first step in the editing process for the artist is to type their address in the search bar and then click the Search icon. The search function zooms to the correct address and displays it in a graphics layer. The second step is to close the Search Results window and switch the basemap to imagery from the Basemap Gallery to pinpoint the artist's location with a better view of the geographic context. The third step is to select the appropriate feature templates from the palette and finally begin editing. Once the point is displayed on the map, a panel on the right side opens for performing attribute editing. The panel displays different types of mandatory and optional fields. Mandatory fields are marked with a red asterisk $(*)$, and the edit cannot be submitted without filling them out, unlike 
the optional fields (Figure 6-7). The required fields for this project are Name of Organization and Address.

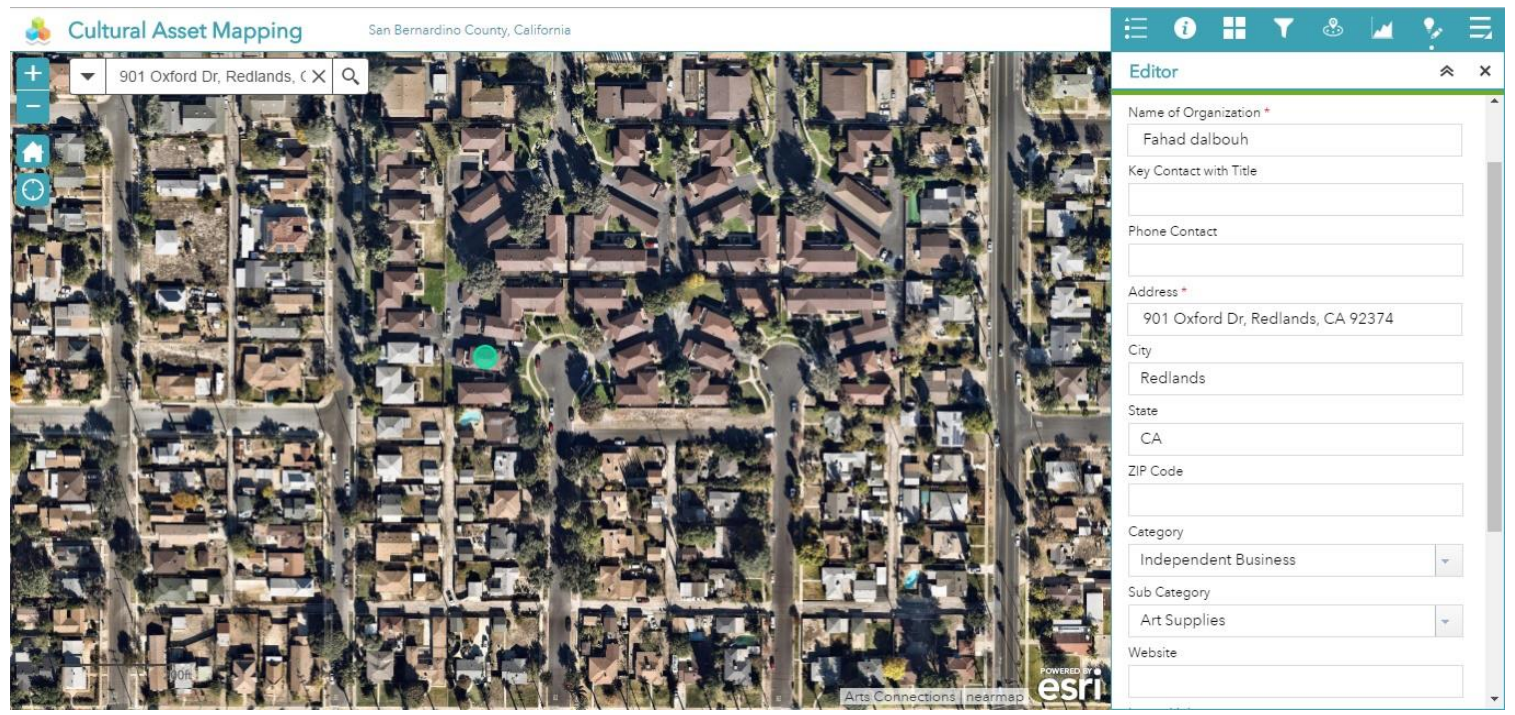

Figure 6-7: Performing Attribute Editing in the Panel for the New Cultural Asset

Once the user submits his entry, this entry will be added to the Cultural Asset Database with a default value of "N" for the Quality field. This means that this entry has not been validated or approved by the Arts Connection staff. Once the staff approves this entry and changes the value from $\mathrm{N}$ to $\mathrm{Y}$, this new cultural asset will then be displayed on the map for the public (Figure 6-8).

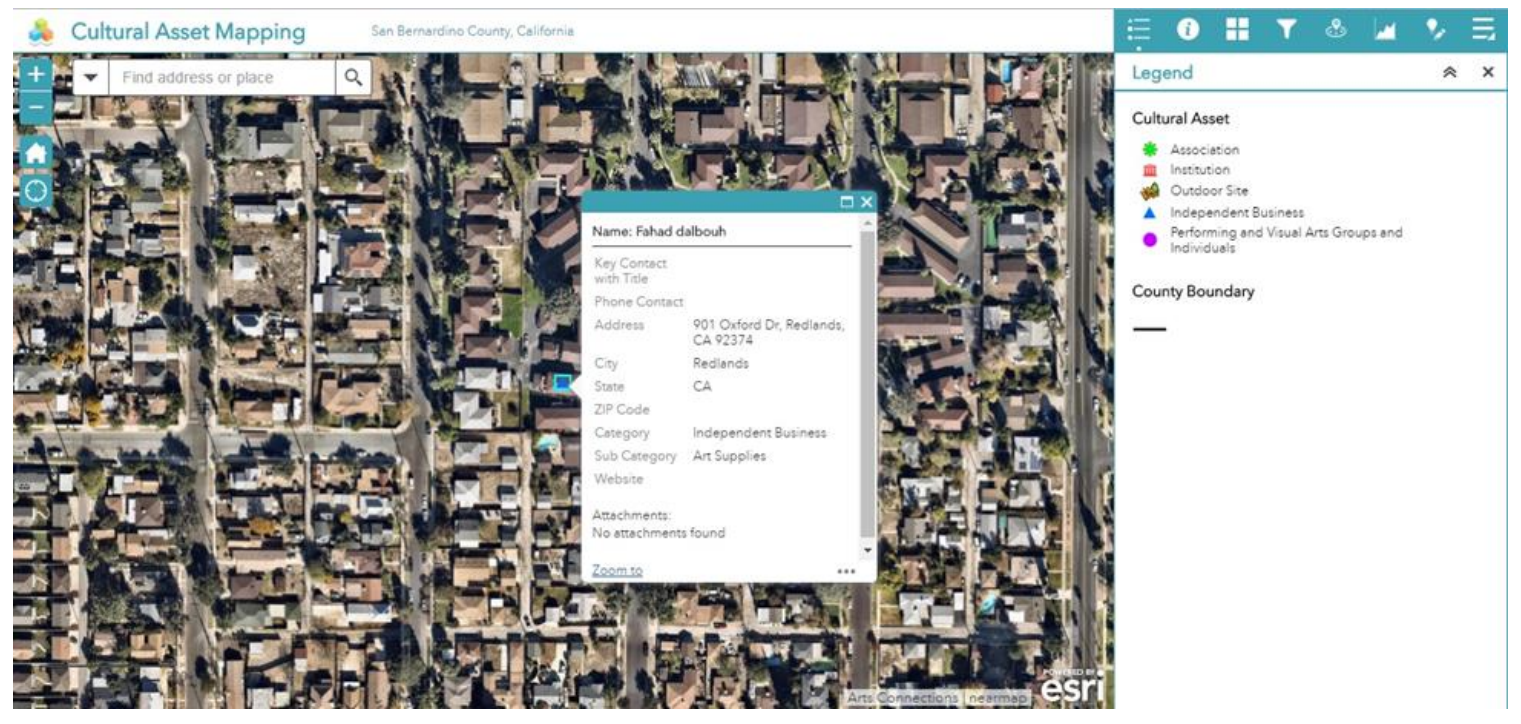




\section{Figure 6-8: The Final Map that Include the New Asset}

\subsection{Analysis Results}

This section demonstrates the results of the many analyses that were conducted for the examination and visualization of the cultural asset patterns. Two scales of analysis were applied to address different questions; one was related to the block group level, and the other one was based on the city level.

\subsubsection{Cultural Assets Density Map}

Figure 6-9 shows a density map of the collected cultural assets within San Bernardino

County. The Kernel Density tools, from the Spatial Analyst toolbox within ArcMap, were used to create the raster surface map. Key to this analysis was identifying areas of concentration or clusters of cultural assets. Where the color is dark red, the cultural assets are concentrated the most, while dark blue represents less concentration. 


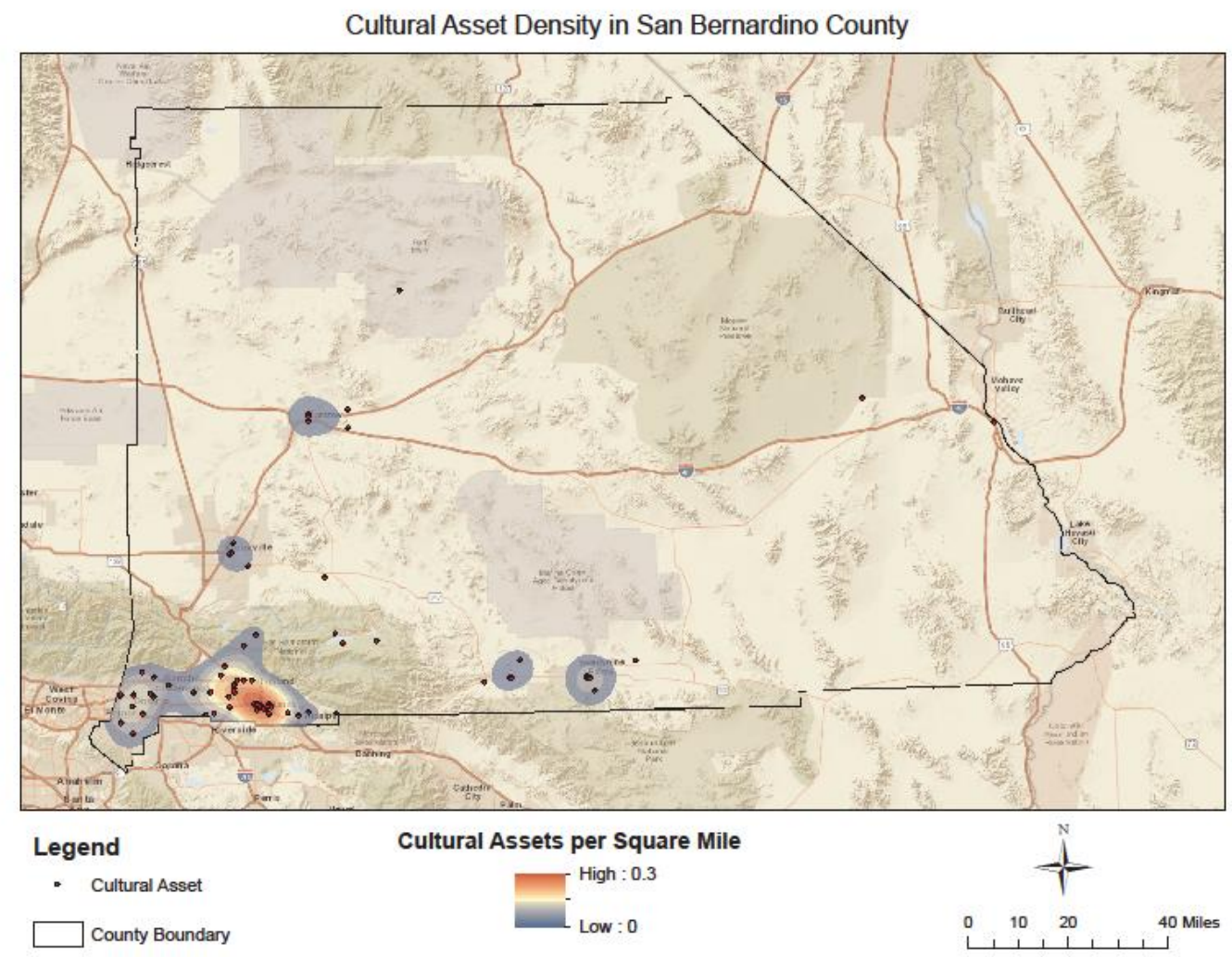

Figure 6-9: Cultural Assets Density Map

The map shows the densest of the collected cultural assets appear to be closer to the border of San Bernardino County in the lower left corner where most densely populated cities are located in this county.

\subsubsection{Spatial Distribution of Cultural Assets}

The client wanted to find out the percentage of residents within San Bernardino County who can reach the collected cultural assets within 15 minutes of driving. To complete this study analysis, a series of polygons that represent the distance that can be reached from a cultural asset within a 15-minute drive had to be created. These polygons are known as service area polygons. Also, the demographic data for 2013 and street data, were needed and they were obtained from the American FactFinder website and Esri, respectively. A 
15-minute service area was calculated for each of the collected cultural assets by using the ArcGIS Network Analyst extension. The process was begun by building a network dataset that would then be used for creating the service area. ArcMap was used to accomplish both tasks.

After creating the service area, all the polygons were aggregated into one polygon by using the Dissolve tool from the Data Management toolbox inside ArcMap. This polygon was then used to select the demographic data, at the block group level, that fell completely inside the polygons. Then, the ratio of the selected features to San Bernardino County residents was calculated. It was found out that $82 \%$ of San Bernardino County residents are within 15 minutes' drive of one of the collected cultural assets. Figure 6-10 shows the result of the analysis, including the percentage number. 


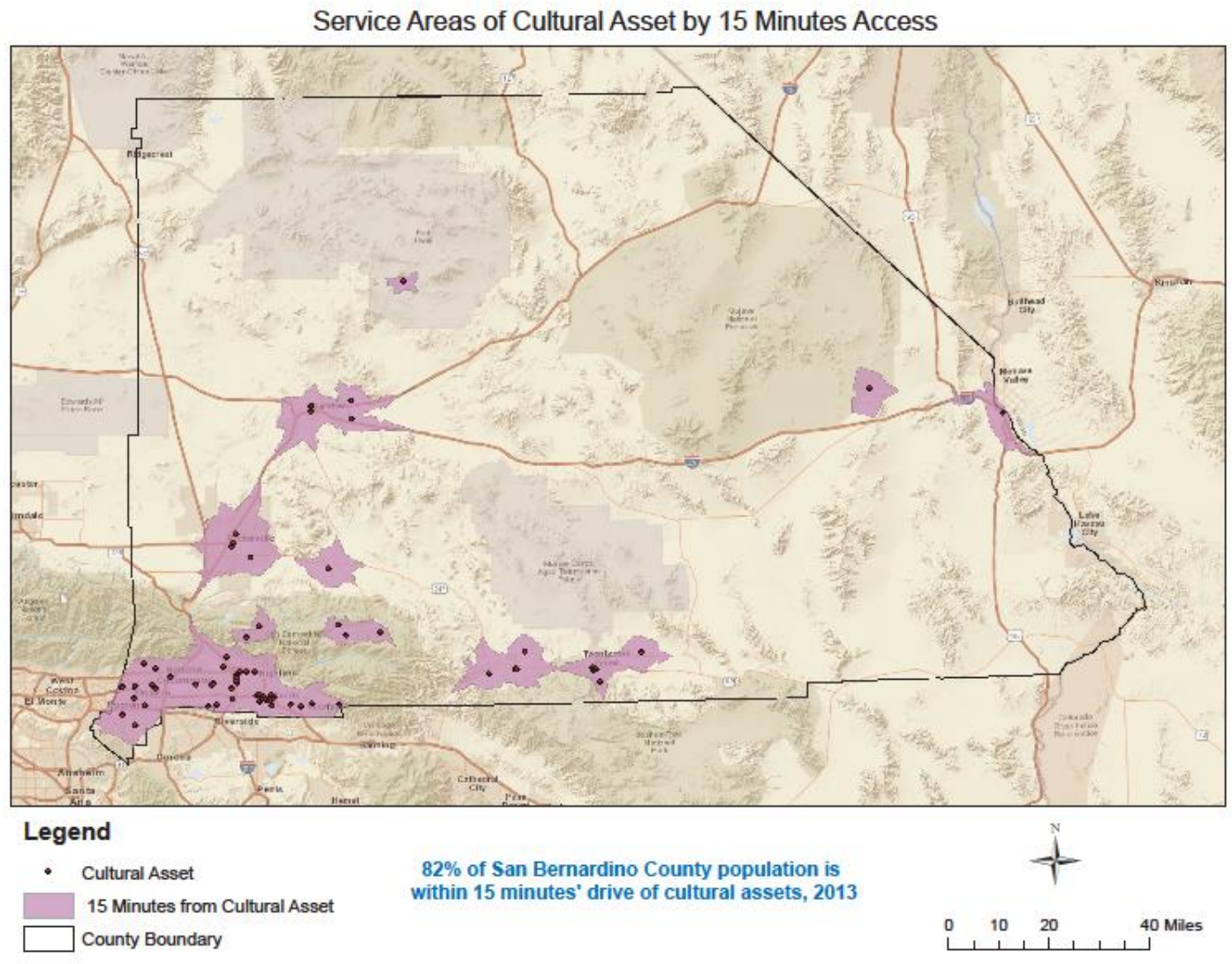

Figure 6-10: Service Areas of Cultural Asset by 15 Minutes' Drive

Another map, in which the size of the symbol varies in proportion to the number of the cultural assets at the city level for San Bernardino County, was required for easily depicting the number of cultural assets that each city has. Therefore, the aggregation of cultural asset points was required to get the number of cultural asset within each city's boundaries. The Spatial Join tool was used in ArcMap to accomplish this task. This resulted in a new feature class containing the attributes for both city boundaries and cultural assets. In Figure 6-11, unique colors and symbols represent the number of cultural assets for each city, using four range-graded classes. Because each class is a unique range of values, any particular symbol can be represented more than once in the map. 


\section{Cultural Assets in San Bernardino County Cities}

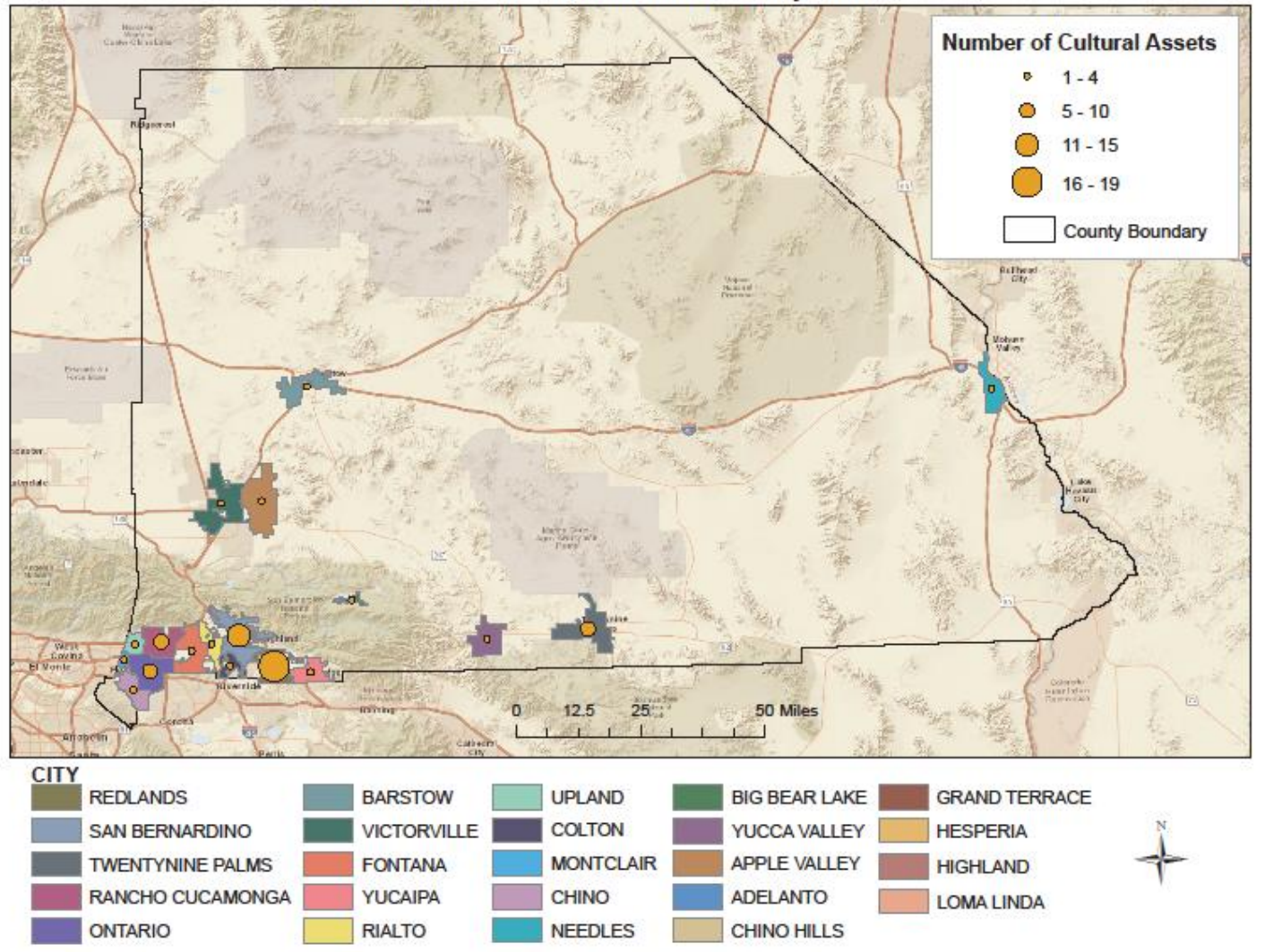

\section{Figure 6-11: Number of the Collected Cultural Assets Shown with Proportional Circles for each City in San Bernardino County}

The top three cities that contain the most cultural assets are Redlands, San

Bernardino, and Twentynine Palms; while the bottom cities include Needles, Big Bear

Lake, Yucaa Valley and Apple Valey. Table 6-1 summarizes the amount of the collected cultural assets in San Bernardino County. 
Table 6-1 Number of Cultural Assets by Citiy in San Bernardino County

\begin{tabular}{|l|c|l|c|}
\hline \multicolumn{1}{|c|}{ City } & $\begin{array}{c}\text { Number of } \\
\text { Cultural Assets }\end{array}$ & \multicolumn{1}{c|}{ City } & $\begin{array}{c}\text { Number of } \\
\text { Cultural Assets }\end{array}$ \\
\hline Needles & 1 & Victorville & 3 \\
Big Bear Lake & 1 & Fontana & 3 \\
Yucca Valley & 1 & Yucaipa & 3 \\
Apple Valley & 1 & Barstow & 4 \\
Rialto & 2 & Rancho Cucamonga & 5 \\
Upland & 2 & Ontario & 5 \\
Colton & 2 & Twentynine Palms & 6 \\
Montclair & 2 & San Bernardino & 13 \\
Chino & 2 & Redlands & 19 \\
\hline
\end{tabular}

\subsubsection{Spatial Proximity between Cultural Assets and Population}

This analysis aims to examine and explore the distribution of cultural assets relative to some underlying covariate such as the population density distribution. Visualizing cultural assets and the population density can help to determine and detect the extent of their spatial relationships. Therefore, the census block group polygon, which contains the population information, was converted into points based on their centroids, and then the kernel density was calculated based on the population field for these points. The Natural Breaks classification method and a graduated color map, with five classes of cultural assets and a census block group per 1,000 people, were applied to map density ranges. The location of cultural assets relative to population density is depicted in Figure 6-12. 
Comparison of Spatial Distributions of People and Cultural Assets
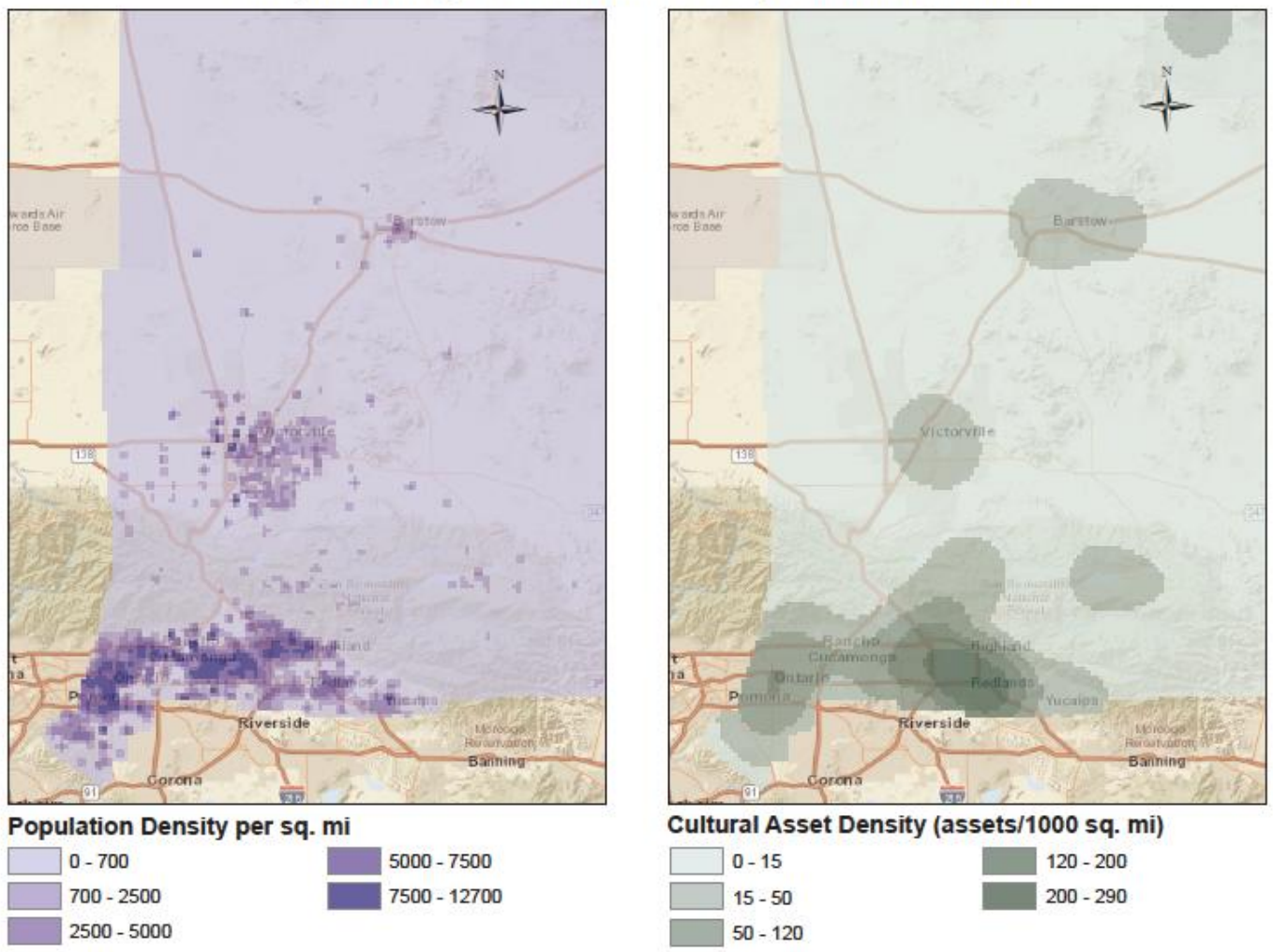

Figure 6-12: Comparison Spatial Distribution of People and Cultural Assets

By looking at the collected cultural assets and population density maps, it is apparent that cultural assets are much more likely to coincide with greater population density. This is especially obvious in the lower left corner of the map, where there are the most cities and people in San Bernardino County. 


\subsection{Summary}

There are two main purposes for the web map application that was built for the Arts Connection, the arts council of San Bernardino County. First, the web application provides a way for residents to visualize, browse, locate, and filter data concerning the cultural assets that are within San Bernardino County. Second, the application allows anyone in the community to edit a point's geometry and attributes according to predefined categories of cultural assets. It also enables them to attach information regarding asset, such as brochure about upcoming events and festivals. Finally, the chapter looked at the results of the many statistical analyses that were conducted to examine the distribution of cultural assets relative to the population at the block group and city levels. 


\section{Chapter 7 - Conclusions and Future Work}

This project was completed for Arts Connection, which is the arts council of San

Bernardino County. The council wanted to replace the existing Geoform application, which does not specify categories of cultural assets and is short of functionality, with a more sophisticated application that would encompass all the aspects of cultural assets that already met the council's specifications as well as enhance and develop new functionality.

\subsection{Summary of Deliverables}

There were three primary objectives for this project. The first objective was to design the Cultural Asset Mapping Project (CAMP) geodatabase according to the client's design. The second objective was to convert, geocode, clean and prepare the data to be published as a hosted feature layer. This enabled the feature access capability, allowing end users to edit the data behind the map service. The third objective was to develop a new web map application that met the client's needs.

These objectives were accomplished through the creation of the cultural asset geodatabase with subtypes and domain associations. This required using ArcCatalog as well as the publishing of a feature service by using ArcMap, accessed by the client's ArcGIS Online organizational account. Additionally, the development of the new web map application, using Web App-Builder for ArcGIS (WABA) integrated edition, was required. The integrated edition of WABA was used to design the user interface (UI) and configure the functionalities of the web map. The project concluded with use case scenarios of the application and analysis results such as cultural asset density, spatial 
distributions and proximity, and the present number of cultural assets in each city of San Bernardino County.

The final deliverables for this project consisted of products and services that, as of this writing, are to be presented to the client. The project deliverables include a file geodatabase, feature services, and a web map application. Table 7-1 lists the deliverables with descriptions.

\section{Table 7-1 Deliverables Item}

\begin{tabular}{|c|l|}
\hline Final deliverable & \multicolumn{1}{c|}{ Description } \\
\hline A file geodatabase & $\begin{array}{l}\text { A complete file geodatabase format where the client can store, } \\
\text { retrieve and update the cultural assets' information }\end{array}$ \\
\hline Feature services & $\begin{array}{l}\text { Publishing a feature service from the file geodatabase to the } \\
\text { client's ArcGIS Online account }\end{array}$ \\
\hline A web map application & $\begin{array}{l}\text { An application that allows users to view the distribution and } \\
\text { related information of the collected cultural assets by using map, } \\
\text { and allows anyone in the community to add, query, search, and } \\
\text { locate particular assets within San Bernardino County. }\end{array}$ \\
\hline Analytics Maps & $\begin{array}{l}\text { The different maps that were designed to detect the distribution of } \\
\text { cultural asset }\end{array}$ \\
\hline
\end{tabular}

\subsection{Future Work}

Upon completion of all the client's requirements for this project, several ideas were proposed for future work. To begin with, the diversity of cultural assets could be expanded and deepened over time to capture the full range of cultural assets. This may involve creating new categories or sub-categories in the database. Regular community meetings with the client would be useful for identifying other community assets and sharing opinions about which asset would be considered more valuable than others.

During this project, only point features were editable via the web application by the end user. It would be a significant improvement to enable users to edit lines and polygon 
features as well, since some cultural assets can be represented by using line or area symbols. For example, a particular street within San Bernardino County could be identified as an asset by the community residents. Integrating socio economic, demographic and many other types of variables into the application would help the communities to discover proximity relationships, and analyze the impact of different factors. This analysis could lead to improving community life.

Another area of expansion could involve improving functionality of the web application by customizing the original application. For example, the Near Me widget could be enhanced by making the buffer distance around the desired location based on the network dataset so that it could match with the routing service. Also, the search bar could be embedded inside the Smart Editor widget to facilitate the editing process for the end user. With AppStudio for ArcGIS, the client could convert the web map into crossplatform native apps. This was an intent of this project, but because of time constraints, it was decided to postpone for future work. 



\section{Works Cited}

Agrios, B., \& Mann, K. (2010). Getting in Touch with Volunteered Geographic Information. ArcUser Online. Retrieved from http://www.esri.com/news/arcuser/0610/vgitutorial.html

Baeker, G., Bulick, B., \& Stasiuk, V. (2005). Cultural planners’ forum. Retrieved from http://www.kultruplan oresund.dk/cultural-planning-forum-notes/

Blais, D. M. (2012). Creative Vitality in Detroit - the Detroit cultural mapping project report. Retrieved from: http://kresge.org/ the Detroit cultural mapping project/

Blais, D. M. (2014). City of Windsor cultural mapping project report. Retrieved from http://www.citywindsor.ca/ final Windsor cultural mapping project/

City of Austin. (2016). Cultural Asset Mapping Project. Retrieved from City of Austin: https://austintexas.gov/ Cultural Asset Mapping Project/

Creative City Network of Canada and 2010 Legacies Now. (2012). Cultural Mapping Toolkit. Retrieved from:

http://www.creativecity.ca/database/files/library/cultural_mapping_toolkit.pdf

Favretto, A. (2010). API, Cloud computing, WebGIS and cartography. Networks and

Communication Studies, NETCOM, 24(3), 245-260. doi: 10.4000/netcom.386

$\mathrm{Fu}, \mathrm{P}$. (2015). Getting to Know Web GIS. Redlands: Esri Press.

Fu, P., \& Sun, J. (2011). Web GIS Principles and Applications. Redlands: Esri Press.

Guidry, M. (2011). A Collaborative Web Application for the Lebu Migration (Master's thesis, University of Redlands). Retrieved from http://inspire.redlands.edu/gis_gradproj/51

Hutsel, A. (2012). A Web GIS for the Economic Department of Highland, California (Master's thesis, University of Redlands). Retrieved from http://inspire.redlands.edu/gis_gradproj/65

Kretzmann, J. \& Mcknight, J. (1993). Building communities from the inside out: A path toward finding and mobilizing a community's assets. Retrieved from: http://www.abcdinstitute.org/publications/basicmanual/

Los Angeles County Arts Commission. (2013). Project Willowbrook: Cultural asset mapping report. Retrieved from http://www.lacountyarts.org/willowbrook/

Portland State University. (2010). Arts and culture asset mapping. Retrieved from https://www.pdx.edu/sites/www.pdx.edu.ims/files/assetsartsculture.pdf

Senaratne, H., Mobasheri, A., Ali, A. L., Capineri, C., \& Hacklay, M. (2016). A review of volunteered geographic information quality assessment methods. International Journal of Geographical Information Science, 1-27. doi: 10.1080 13658816.2016.1189556

Sui, D, Elwood, S. \& Goodchild, M. (2012). Crowdsourcing Geographic Knowledge: Volunteered Geographic Information (VGI) in Theory and Practice. Springer Science \& Business Media, 105-122. doi: 10.1007/978-94-007-4587-2_7

Voigt, R. (2011, Winter). Cultural Asset Mapping. Planning Commissioners Journal. Retrieved from http://plannersweb.com/2011/01/cultural-asset-mapping/

Wilson, M. (2004). Managing Cultural Resources with GIS: Museum Collections. Retrieved from: https://www.nps.gov/gis/mapbook/tech/52.html 

